\title{
Pulsed IRSL: A stable and fast bleaching luminescence signal from feldspar for dating Quaternary sediments
}

Tsukamoto, Sumiko; Kondo, Reisuke; Lauer, Tobias; Jain, Mayank

Published in:

Quaternary Geochronology

Link to article, DOI:

10.1016/j.quageo.2017.05.004

Publication date:

2017

Document Version

Peer reviewed version

Link back to DTU Orbit

Citation (APA):

Tsukamoto, S., Kondo, R., Lauer, T., \& Jain, M. (2017). Pulsed IRSL: A stable and fast bleaching luminescence signal from feldspar for dating Quaternary sediments. Quaternary Geochronology, 41, 26-36.

https://doi.org/10.1016/j.quageo.2017.05.004

\section{General rights}

Copyright and moral rights for the publications made accessible in the public portal are retained by the authors and/or other copyright owners and it is a condition of accessing publications that users recognise and abide by the legal requirements associated with these rights.

- Users may download and print one copy of any publication from the public portal for the purpose of private study or research.

- You may not further distribute the material or use it for any profit-making activity or commercial gain

- You may freely distribute the URL identifying the publication in the public portal 
Pulsed IRSL: a stable and fast bleaching luminescence signal from feldspar for dating Quaternary sediments

Sumiko Tsukamoto ${ }^{a}$, Reisuke Kondo ${ }^{b}$, Tobias Lauer ${ }^{c}$ and Mayank Jain ${ }^{d}$

${ }^{a}$ Leibniz Institute for Applied Geophysics, Stilleweg 2, Hannover 30655, Germany

${ }^{\mathrm{b}}$ Kogakkan University, 1704 Kodakushimoto-cho, Ise, 516-8555 Japan

${ }^{\mathrm{c}}$ Department of Human Evolution, Max Planck Institute for Evolutionary Anthropology, Deutscher Platz 6, D-04103 Leipzig, Germany

d Center for Nuclear Technologies, Technical University of Denmark, DTU Risø Campus, DK-4000, Roskilde, Denmark

\section{Abstract}

Elevated temperature post-infrared infrared stimulated luminescence (post-IR IRSL; pIRIR) dating method using feldspar has led to a significant advancement in dating Quaternary sediments, as this signal has been shown to be stable on geological time scales. In comparison to the conventional IRSL, the pIRIR signal is nearly free from anomalous fading, but it is more difficult to reset during daylight exposure; the latter characteristic may give rise to age over-estimation in some environments because of partial bleaching. The pulsed IRSL signal has also been known to be less affected by anomalous fading, when the signal is recorded during the off-time of LED stimulation pulses. In this study, we compare the signal bleachability, thermal and athermal stability, and age estimates derived using different measurement methods, i.e., pulsed IRSL measured at $50^{\circ} \mathrm{C}$ (pulsed $\mathrm{IR}_{50}$; subscripts refers to measurement temperature), continuous wave (CW) pIRIR 225 and pIRIR ${ }_{290}$ signals, as well as the two $I_{50}$ signals measured as a part of the pIRIR protocols. This comparison is carried out for 3 samples taken from Late Quaternary fluvial sediments, which have independent age estimates from radiocarbon dating and tephrochronology. We observe that under exposure to solar simulator, the pulsed $\mathbb{I}_{50}$ signal bleaches as rapidly as the $\mathrm{CW} \mathrm{IR}_{50}$, and much more rapidly than the pIRIR signals. Furthermore, the pulsed $I_{50}$ signal is also as stable as the pIRIR signals, especially when the middle part of the decay curve is used for signal intensity calculation. 
1. Introduction

The post-infrared infrared stimulated luminescence (post-IR IRSL, hereafter pIRIR) dating method of feldspar, including both two-step pIRIR (Thomsen et al., 2008) and multi-elevated-temperature (MET)pIRIR ( $L i$ and Li, 2011) have become robust methods for dating Quaternary sediments. However, the pIRIR signal appears to be more difficult to bleach than the IRSL signal measured at low temperature, typically at $50^{\circ} \mathrm{C}\left(\mathrm{IR}_{50}\right.$; hereafter the subscript refers to the measurement temperature) (e.g. Buylaert et al., 2012). With increasing preheat and stimulation temperature the pIRIR signal tends to become more stable, but at the cost of poorer bleachability (Li and Li, 2011; Kars et al., 2014; Colarossi et al., 2015); thus, it appears that there is a trade-off between signal stability and its ability to reset prior to sediment burial. The post-IR IRSL signal measured at $290^{\circ} \mathrm{C}\left(\mathrm{pIRIR}_{290}\right)$ is thought to be stable and there is no need for fading correction (e.g. Buylaert et al., 2012), whereas the pIRIR ${ }_{225}$ signal less stable and requires fading correction. However, $\mathrm{pIRIR}_{225}$ signal is more bleachable than pIRIR 290 , and is generally preferred for dating sediments from environments where full bleaching is less likely (e.g. Smedley et al., 2016). The pIRIR signal at a lower temperature (e.g. pIRIR ${ }_{150}$ ) is generally preferred for young (e.g. Holocene) sediments (Reimann and Tsukamoto, 2012). However, there has been no consensus of how the preheat and stimulation temperatures should be selected (Zhang et al., 2015).

The pulsed IRSL signal has been also reported to be more stable than the continuous wave (CW) IRSL signal (Sanderson and Clark, 1994; Tsukamoto et al., 2006; Jain and Ankjærgaard, 2011; Jain et al., 2015), although this method has not been tested as widely as the pIRIR signal. Roskosch et al. (2015a,b) chose to use the pulsed IR $_{50}$ instead of the pIRIR signal for dating fluvial and glaciofluvial sediments, assuming that the slow bleachability of the pIRIR signal was not suitable for their samples. Jain et al. (2015a) showed that the residual dose from the modern sediments for the pulsed IRSL signal is much lower than that for the pIRIR signal and presumed that the pulsed IRSL signal bleaches faster than the pIRIR signal. Jain et al. (2015a) also observed that both pIRIR ${ }_{290}$ and pulsed IRSL signals were in saturation in a sample with an age estimated 3.6 Ma. Thus, it appears that the pulsed IRSL signal has a better bleachability, but similar stability compared to the pIRIR ${ }_{290}$ signal. In this paper, we characterise the pulsed IRSL signal in terms of bleaching, and thermal- and athermal-stability and compare these characteristics to those of the pIRIR signals $\left(I_{R} R_{225}\right.$ and $\left.p I R I R_{290}\right)$ and the corresponding IRSL signals $\left(\mathbb{R}_{50}\right)$ measured as part of the pIRIR protocol. We also compare the pIRIR $225, \mathrm{pIRIR}_{290}$ and pulsed $I R_{50}$ ages for three fluvial sediment samples, which have independent age control.

\section{Samples}


Three fluvial sediment samples having age control were used in this study (Table 1, Fig. 2). Sample SW-II was taken from the Roman time harbour sediment in Cologne, Germany (Fig. 1), excavated by the construction works of the subway (Lauer et al., 2011a). The fluvial sediment at the former harbour of the Rhein contains broken ceramics and bricks from Roman time, and the harbour was known to have been used in the early first century (Dietmar and Trier, 2006). Three charcoal samples (RC-1, -2, and -3) which were found above and below SW-II were dated between $2010 \pm 55$ a BP and $2080 \pm 85$ a BP by radiocarbon (Lauer et al., 2011a). The calibrated radiocarbon ages are all consistent to the first century AD (Table 1). The OSL age of SW-II was calculated by various statistical methods; the mean and the 3 component minimum age model (MAM-3) were reported to be $3460 \pm 350$ a and $1690 \pm 590 \mathrm{a}$, respectively (Lauer et al., 2011a). The latter age was recalculated with the new version of MAM-3 and yielded $1980 \pm 330$ a using $15 \%$ overdispersion.

Sample MHT-II was taken from an outcrop at Monheim-Hitdorf, 20 km north of Cologne (Fig. 1), where a 6-m thick sediment is intercalated with pumices of the Laacher See Tephra. Sanidine phenocrysts of the Laacher See Tephra were dated to $12900 \pm 560$ a by the ${ }^{40} \mathrm{Ar} /{ }^{39} \mathrm{Ar}$ method (van den Bogaard, 1995). Hadjas et al. (1995) dated macrofossils in varved lake sediments of Holzmaar, Eifel Volcanic Field, Germany. The calibrated ${ }^{14} \mathrm{C}$ age of the Laacher See Tephra was reported to be 12,201 \pm 224 cal. BP in the paper. However, the calibrated ages of two subsamples closest to the tephra by Intcal 13 are ranging from 12830 to $13266 \mathrm{cal} \mathrm{BP}$ and from 13071 to $13413 \mathrm{cal} \mathrm{BP}$, in agreement with the ${ }^{40} \mathrm{Ar} /{ }^{39} \mathrm{Ar}$ age. The fluvial sediment studied by Lauer et al. (2011b) can be considered to be slightly younger than the eruption age of the Laacher See Tephra. Lauer et al. (2011b) dated three samples from the fluvial sediment sequence (MHT-I, -II, and -III) which yielded similar quartz OSL ages from $11.6 \pm 0.7$ to $11.7 \pm 1.0 \mathrm{ka}$. MHT-I, which was taken $4 \mathrm{~m}$ below MHT-II, was also measured with $\mathrm{K}$ feldspar using pIRIR ${ }_{225}$ and post-IR yellow stimulated luminescence signals (Lauer et al., 2012), which are consistent with the quartz OSL age, $12.2 \pm 1.2 \mathrm{ka}$ and $11.5 \pm 1.2 \mathrm{ka}$, respectively.

Sample LUM-3291 was collected from fluvial sediment of the Tanahara-Harataima (Th) terrace (Kaizuka and Moriyama, 1969) of Sagamihara River, at Muryokoji in Sagamihara, near Tokyo, Japan (Fig. 1). The fluvial sediment here is overlain by $\sim 3.5 \mathrm{~m}$ tephric loess, which is a mixture of loess, local dust and tephra from small scale eruptions. About $40 \mathrm{~cm}$ from the bottom of the tephric loess, a widespread Aira Tanzawa (AT) tephra from southern Kyushu has been found (Research Group of Gemorphology and Geology in Sagamihara, 1984). This tephra was dated to 25,120 \pm 270 BP (from 28577 to 29831 cal BP) by radiocarbon of charcoal and humic acid samples taken close to the source area (Miyairi et al., 2004). This tephra was also found in the varved sediment in the Lake Suigetsu, and the age of AT has been estimated to 30,009 \pm 189 a cal BP SG06 2012 (Smith et al. 2013). The depositional 
age of the fluvial sediment has been estimated to be slightly older than the age of AT tephra (Research Group of Geomorphology and Geology in Sagamihara, 1984; Kubo, 1997).

\section{Methods}

Sand sized K-feldspar samples between 150 and $200 \mu \mathrm{m}$ in diameter were prepared for all three samples. The standard preparation procedure including density separation of $d<2.58$ was made at Leibniz Institute for Applied Geophysics for LUM-3291. Two other samples (SW-II and MHT-II) were separated using the flotation technique (Miallier et al., 1983) at University of Freiberg. All samples were measured using large aliquots containing a few hundred grains.

Gamma spectrometry was performed using $50 \mathrm{~g}$ of dried material for LUM-3291 for estimating the environmental dose rate. The radioactivity data for SW-II and $\mathrm{MH}-\mathrm{II}$ were obtained from Lauer et al. (2011a and b). The annual dose rate for the K-feldspar samples was calculated using the natural water content, the conversion factors of Guerin et al. (2011), the internal K concentration of $12.5 \pm 0.5 \%$ (Huntley and Baril, 1997) and an a-value of $0.09 \pm 0.02$ (Balescu et al., 2007).

All luminescence measurements were performed with an automated Risø TL/OSL DA-20 reader, equipped with pulsed-stimulation and Photon-Timer attachments (Lapp et al., 2009). The IRSL signal is filtered through a combination of BG39 and 7-59 filters transmitting between 380 and $460 \mathrm{~nm}$. Both for the time resolved (TR)-IRSL and the pulsed-IRSL measurements, the pulse width was set to $100 \mu \mathrm{s}$ ('on'-time) and the period between two stimulation pulses was set to $400 \mu$ s ('off'-time). The off-time pulsed IRSL signal was detected after rejecting the initial $21.5 \mu$ s signal. The normal setting of the Ris $\varnothing$ pulsed OSL card only allows to reject up to $5 \mu$ s of the initial off-time signal. We added a $330 \mathrm{pF}$ capacitor on top of the existing $100 \mathrm{pF}$ one on the pulsing card, which made the gating time 4.3 times longer.

\section{TR-IRSL signal}

Fig. 3a shows a 3D plot of a TR-IRSL measurement of an aliquot of $\mathrm{MH}-\mathrm{Il}$ after giving a regenerative dose of $40 \mathrm{~Gy}$ and preheat at $250^{\circ} \mathrm{C}$ for $60 \mathrm{~s}$. The total measurement period was $500 \mathrm{~s}$; thus Fig. $3 \mathrm{~b}$ represents a sum of the individual time-resolved data corresponding to 1 million IR pulses. The TR-IRSL signal rises gradually when the stimulation light is switched on, and decays after the light is turned off. From the TR-IRSL data, two decay curves were extracted using 1) on-time (0-100 $\mu \mathrm{s})$ data and 2) offtime data after rejecting the initial $21.5 \mu \mathrm{s}$. As can be seen in Fig. $3 \mathrm{c}$, the signal intensity in the off-time 
is only about $\sim 2.5 \%$ of that in the on-time data. In Fig. $3 \mathrm{~d}$, the decay curves were normalised to the initial intensity. The decay rate of the off-time signal is slower than the on-time signal.

The IRSL signal from feldspar is understood to originate from decay of the excited state of the trapped electrons by tunnelling or localised diffusion within the band tail states, leading to recombination with the holes at the nearest-neighbouring sites (e.g. Jain and Ankjærgaard, 2011; Jain et al., 2012, 2015b). As the IR stimulation continues, the distance between the trapped electrons and their nearest holes should gradually increase leading to a slower decay of the trapped electron population with time; this leads to a decay form following a Becquerel function (Pagonis et al., 2014; Jain et al., 2015b). Similarly, since the off-time IRSL signal has been shown to arise from more distant electron-hole pairs (Jain and Ankjærgaard, 2011) compared to the on-time signal, its decay should also be relatively slower; this is confirmed in Fig. 3d.

\section{Bleachability}

Poolton et al. (2002) suggested that the bleaching rate of the IRSL signals decreases with increasing stimulation temperature. This was shown experimentally by Li and Li (2011) who measured the bleaching curves of the MET-pIRIR signals stimulated between 50 and $250^{\circ} \mathrm{C}$. Buylaert et al. (2012) presented that the pIRIR ${ }_{290}$ signal is much harder to bleach than the $I_{50}$ signal. They also showed that the $I_{50}$ signal with a higher preheat temperature $\left(320^{\circ} \mathrm{C}\right.$ as a part of the pIRIR $R_{290}$ protocol, hereafter pre-pIR $R_{290}$ ) was more difficult to bleach than the $\mathbb{I R}_{50}$ with a lower temperature preheat $\left(250^{\circ} \mathrm{C}\right)$. Colarossi et al. (2015) compared the bleachability of four IRSL signals from the pIRIR ${ }_{225}$ and pIRIR 290 protocols: i.e., $I_{50}$ (pre-pIR $\mathbb{R}_{225}$ ), $I R_{50}$ (pre-pIR 290 ), pIRIR 225 and $p I R I R_{290}$. The bleaching rates of these signals varied systematically from the fastest to the slowest in the following order, $\mid R_{50}\left(p r e-p \mid R_{225}\right)>$ $I_{50}($ pre-pIR 290$)>$ pIRIR $225>$ pIRIR 290 .

In this study, we compare the bleachability of the $I R_{50}$ (pre-pIR ${ }_{225}$ ), $I R_{50}($ pre-pIR 290 ), pIRIR 225 , pIRIR 290 and pulsed $I_{50}$ signals for two samples, MH-II and LUM-3291. To eliminate the possible effect of the variation in natural dose across the (sub)samples, we first carried out laboratory zeroing of the signal by a double exposure to IR LEDs in the Ris $\varnothing$ reader at $350^{\circ} \mathrm{C}$ for $200 \mathrm{~s}$, followed by a regeneration dose of $20 \mathrm{~Gy}$; there was no detectable IRSL signal after the zeroing. Only 3 aliquots were beta irradiated at a time, and they were brought immediately to a solar simulator (Hönle SOL2) for bleaching, in order to minimise the delay between the irradiation and the start of the bleaching. Three aliquots per each bleaching duration were bleached between 0 and 4 hours (without bleach, 3 minutes, 10 minutes, 20 
minutes, 1 hour, 2 hour and 4 hour) in the SOL2, and the $D_{e}$ values were measured using pIRIR 225 , pIRIR 290 and pulsed $I R_{50}$ protocols (Table 2).

Fig. 4a shows the bleaching curves of $M H-I I$ for the $I R_{50}$ (pre-pIR $R_{225}$ ), $I R_{50}$ (pre-pIR 290 ), pIRIR $R_{225}$ and pIRIR 290 , and pulsed $I R_{50}$ plotted as remaining $D_{e}$ value vs. the bleaching time. The initial signal $(0-4 s)$ minus the background of the last $20 \mathrm{~s}$ of the decay curves were used to calculate the $D_{e}$ values. For the pulsed $I_{50}$, equivalent integration periods to the CW-IRSL data were used (i.e. 5 times CW-IRSL data). Each data point represents an arithmetic mean of 3 aliquots and 1- $\sigma$ standard error. It can be clearly seen that the pulsed $I R_{50}$ signal bleaches as fast as the $C W I R_{50}$ signals (pre-pIR $R_{225}$ and pre-pIR 290 ) and bleaches much faster than the pIRIR ${ }_{225}$ and pIRIR 290 signals. The same tendency is observed from LUM3291 (Fig. 4b), although the data have larger uncertainty due to the lower signal intensity for this sample.

We also examined whether there is any dependence of the $D_{e}$, measured after bleaching, on the integral section of the IRSL decay curves used for the $D_{e}$ estimation. The 'remaining' $D_{e}$ values for the different signal integration periods, $0-4 \mathrm{~s}, 4-12 \mathrm{~s}, 12-20 \mathrm{~s}$ and $20-40 \mathrm{~s}$, are plotted for the sample MHT-II in Fig. 4c and d. All the signals become harder-to-bleach towards the latter part of the decay curve, however, the latter part of the $\mathrm{IR}_{50}$ signal, both $\mathrm{CW}$ and pulsed, are still more rapidly bleachable than the initial part of the pIRIR signals.

\section{Anomalous fading}

Fading tests were conducted using 6 aliquots for the five signals discussed above using a generation dose of $40 \mathrm{~Gy}$ and a test dose of $10 \mathrm{~Gy}$, and delays up to 40 hours. The $\mathrm{g}_{2 \mathrm{days}}$-values of all signals for all the three samples using the initial signal (0-4 s) are shown in Fig. $5 a$. The pulsed $\mathbb{R}_{50}$ fading rate is slightly higher than the two pIRIR signals but lower than the $C W \mathrm{IR}_{50}$ signals, when the initial signal intensity is used. It is interesting to note that the $I_{50}\left(\right.$ pre-pIR $\left.R_{290}\right)$ fading rate is much lower than the $\mathbb{I R}_{50}$ (pre-pIR $\mathrm{R}_{225}$ ) fading rate; this is possibly due to the effect of a higher preheat used in the $\mathrm{pIR}_{290}$ protocol (Jain et al., 2015a, b). When the signal intensity from the later part of the decay curve was used (4-12s, 12-20s and 20-40s), the fading rate of two pIRIR signals and pulsed IRSL signal became indistinguishable (Fig. $5 b-d$ ). The fading rate of all signals tend to decrease towards the later stimulation time, probably due to the increasing electron-hole recombination distance with the stimulation time (e.g. Thomsen et al., 2011; Jain and Ankjærgaard, 2011). 
We also explored time resolved fading in sample $\mathrm{MH}-\mathrm{II}$. A fading measurement using the TR-IRSL $\mathrm{L}_{50}$ signal was performed using two aliquots of $\mathrm{MH}-\mathrm{II}$. The given regeneration and test doses were the same as above (40 and $10 \mathrm{~Gy}$ ) and repeated L/T measurements were done at $50^{\circ} \mathrm{C}$ for $500 \mathrm{~s}$ after a preheat at $250^{\circ} \mathrm{C}$ for $60 \mathrm{~s}$ with delays up to 59 hours. The result is plotted against pulse arrival time in Fig. 6 for the initial part (0-4 s on time) and for the middle part (4-12 s) of the total measurement duration. The fading rate is high during the on-time, and during the off-time it does not drop immediately after the LEDs are switched off but decreases gradually; this confirms the results of Jain and Ankjærgaard (2011). Furthermore, as expected, the fading rates calculated from the middle part of the decay curve are always lower than those from the initial signal for both the on- and off-times. The $g_{2 d a y s}-v a l u e$ becomes consistent with zero for the middle part of the decay curve (4-12s) at around $\sim 200 \mu$ s ( 100 $\mu$ s during the off-time).

\section{Thermal stability}

Thermal stability measurements were conducted to compare the thermal stability of the $\mathbb{I R}_{50}$ (prepIR ${ }_{225}$ ), pIRIR 225 , and pulsed $I R_{50}$ signals. It is already known that the pIRIR signal appears to be thermally more stable than the $\mathbf{I R}_{50}$ signal (e.g. Thomsen et al., 2011; Jain and Ankjærgaard, 2011, Tsukamoto et al., 2012), even though, both these signals are argued to originate from the same trap (Jain and Ankjærgaard, 2011; Andersen et al., 2012). The interpretation of this behaviour is that the thermal stability obtained by a pulse annealing experiment is not just the measure of a trap depth, but the also the stability of an electron-hole pair as a function of the mean electron-hole separation (Jain and Ankjærgaard, 2011; Jain et al., 2015b).

Two aliquots of each sample were irradiated with $40 \mathrm{~Gy}$ and preheated between 260 and $500^{\circ} \mathrm{C}$ (with a $20^{\circ} \mathrm{C}$ increment) for pIRIR 225 and pulsed $I_{50}$ protocols. The result calculated from the initial signal (0-4 s) for MH-II is shown in Fig. 7a. The thermal stability of the pulsed $I_{50}$ signal lies in between the $I_{50}$ (pre-pIR $R_{225}$ ) and pIRIR 225 signals, and the same was observed for the other two samples (the data are not shown). This suggests that the electron-hole separation distance for the pulsed $I_{50}$ signal is greater than the $\mathrm{CW}-\mathrm{IR}_{50}$ signal but shorter than the pIRIR $\mathrm{R}_{225}$ signal. In Fig. $7 \mathrm{~b}$, the data are plotted with different signal integration periods, 0-4s, 4-12 s, 12-20s, and 20-40s. The latter part of the signals become more thermally stable for all signals, also reflecting the increasing distance of the electronhole pair with the stimulation time.

\section{Age comparison}


Dose recovery tests were performed using all three samples and for the three protocols, pIRIR $R_{225}$, pIRIR 290 and pulsed IR ${ }_{50}$ (Table 2). Altogether, eighteen aliquots per sample were bleached in the SOL2 for four hours. For half of the aliquots, a beta dose which is close to the estimated $D_{e}$ value was given, and measured if the protocols can recover the given dose. The remaining aliquots were measured without giving dose, and the residual dose after the 4 hour bleaching was determined. The dose recovery ratio was calculated by dividing the recovered dose with the given dose, after subtracting the measured residual dose. The results are shown in Fig. 8. The dose recovery ratio of all three samples are close to unity for the pIRIR 225 and pulsed $I R_{50}$ signal. However, the dose recovery ratio of the pIRIR 290 signal tends to be greater than unity, while, except for LUM-3291, the dose recovery ratio of the $\mathbb{R}_{50}$ (pre-pIR 225 ) and $I R_{50}$ (pre-pIR $R_{290}$ ) are less than unity.

Between ten and twelve aliquots for each sample were measured to calculate $D_{e}$ values using pIRIR $R_{225}$, pIRIR 290 and pulsed $I R_{50}$ protocols (Table 2). Here, the $I R_{50}$ (pre-pIR 225 and pre-pIR 290 ) signals are not considered because their fading rate was large and the dose recovery ratio was not satisfactory for the two samples, SW-II and MHM-II. The mean $D_{e}$ values were calculated using the initial signal $(0-4 \mathrm{~s})$ for the two pIRIR signals but the middle part (4-40 s) was used for the pulsed $I_{50}$ signal. The fading corrections were conducted based on Huntley and Lamothe (2001). The resulting ages were then compared with independent age control. Fig. 9 shows fading uncorrected and corrected ages in comparison with the independent age control, plotted against the signal integration limit. Only uncorrected ages are shown if the fading rate is statistically consistent with zero.

SW-II was taken from the Roman time harbour sediments in Cologne, known to be in the first century AD. Both radiocarbon ages from charcoal and quartz MAM age of the sample are consistent with the historical evidence, $\sim 2 \mathrm{ka}$, however the quartz mean OSL age of this sample is $3.46 \pm 0.35 \mathrm{ka}$ (Lauer et al., 2011a). Since the bleaching rate of any feldspar luminescence signal is much slower than the quartz OSL signal, we do not expect an age younger than $\sim 3.5$ ka from K-feldspar. Both fading uncorrected $(3.54 \pm 0.38 \mathrm{ka})$ and corrected (3.74 $\pm 0.41 \mathrm{ka})$ ages of pulsed $\mathrm{IR}_{50}$ signal of SW-II are consistent with the quartz mean OSL age of this sample, whereas the $\mathrm{pIRIR}_{225}$ and $\mathrm{pIRIR} \mathrm{R}_{290}$ ages are $5.87 \pm 0.37 \mathrm{ka}$ (6.85 $\pm 0.44 \mathrm{ka}$, fading corrected) and $11.0 \pm 0.7 \mathrm{ka}$ (12.8 $\pm 0.8 \mathrm{ka}$, fading corrected), respectively (Table 3).

MHT-II was collected from the fluvial sediment intercalated with the reworked Laacher See Tephra, which was erupted at $\sim 13 \mathrm{ka}$. Thus, the age of the sediment is expected to be slightly younger than the age of the tephra. The quartz OSL age of $11.6 \pm 0.7 \mathrm{ka}$ for this sample was reported by Lauer et al. (2011b). Fading uncorrected pulsed $I_{50}$ age is slightly younger ( $\left.9.68 \pm 0.55 \mathrm{ka}\right)$ than the quartz OSL age, due to non-negligible fading of this sample ( $1.6 \% /$ decade). The fading corrected age using the 
middle part of the pulsed $\mathbb{R}_{50}$ signal $(11.1 \pm 0.7 \mathrm{ka})$ is in good agreement with the quartz age. The $\mathrm{pIRIR}_{225}$ and pIRIR 290 ages again overestimated the expected age; $14.0 \pm 0.7 \mathrm{ka}$ (17.3 $\pm 1.1 \mathrm{ka}$, fading corrected) for the pIRIR ${ }_{225}, 19.9 \pm 1.1 \mathrm{ka}(23.3 \pm 1.7 \mathrm{ka}$, fading corrected) for the pIRIR 290 .

LUM-3291 is a fluvial sediment consisting of Tanahara-Harataima (Th) terrace of the Sagami River. The AT tephra of 30 ka (Miyairi et al., 2004; Smith et al., 2013) was found in the tephric loess sediment, $\sim 40 \mathrm{~cm}$ from the bottom of the tephric loess, and therefore the fluvial sediment is expected to be slightly older than $30 \mathrm{ka}$. The thickness of the tephric loess above the AT tephra is $3.2 \mathrm{~m}$ (including andosol on top) at the sampled section of LUM-3291 but typically a 5-6 $\mathrm{m}$ thick tephric loess above the AT tephra was observed in the Tanahara-Harataima Terrace (e.g. Kubo, 1997). Thus, a preliminary loess accumulation rate of $\sim 10-20 \mathrm{~cm} / \mathrm{ka}$ can be calculated. We assume that the fluvial sediment is only up to a few thousand years older than the AT. The pulsed $I R_{50}$ age is consistent with the expected age, $33.8 \pm 2.2 \mathrm{ka}$; anomalous fading was not detected from the middle part of the pulsed $I_{50}$ signal and, therefore, no fading correction was conducted. The pIRIR ${ }_{225}$ and $\mathrm{pIRIR}_{290}$ ages are much older; $96.2 \pm 11.5 \mathrm{ka}$ (101 $\pm 12 \mathrm{ka}$, fading corrected) for the pIRIR 225 and $107 \pm 13 \mathrm{ka}$ for the pIRIR ${ }_{290}$ (no fading for this signal; Table 3).

\section{Discussion and conclusions}

We compared the luminescence characteristics of the $I R_{50}$ (pre-pIR $R_{225}$ and pre-pIR 290 ), pIRIR 225 , pIRIR 290 and pulsed $I R_{50}$ signals. The bleachability of the pulsed $I R_{50}$ signal is comparable to the $I R_{50}$ (pre-pIR $R_{225}$ and pre-pIR ${ }_{290}$ ) signals, but its anomalous fading is as low as for the pIRIR ${ }_{225}$ and pIRIR ${ }_{290}$ signals, especially, when the middle part (4-40s corresponding to the on-time) of the pulsed $I R_{50}$ decay curve is used for signal integration. The fading correction of the pulsed $I_{50}$ age was still necessary for two samples, however, this could be due to the instrumental limitation of the pulsing system used in this study with the maximum on-gate delay of $21.5 \mu \mathrm{s}$. Non fading pulsed $I R_{50}$ signal may be measured, if a longer on-gate delay (> $100 \mu \mathrm{s}$ ) is used, as shown in the TR fading test (Fig. 6). The thermal stability data suggest that the pulsed $I R_{50}$ is thermally more stable than the $C W R_{50}$ but less stable than the pIRIR 225 . For our three dating samples, the pulsed $I_{50}$ ages are all consistent with independent age control, while the pIRIR ${ }_{225}$ and pIRIR 290 ages are overestimated. The inaccuracy of the pIRIR ages likely arises due to incomplete bleaching, and additionally, in case of the pIRIR ${ }_{290}$, a poor dose recovery.

For the pIRIR signals there is a tendency that the signals become more difficult to bleach, while the signal stability increases with increasing preheat and stimulation temperatures. This is presumably because of a combination of thermal transfer and the fact that higher temperature pIRIR signals 
originate from more distant electron-hole pairs; it may be inherently more difficult to empty traps, which have distant recombination centres, by athermal fading or by thermal/optical eviction. However, this model does not explain the unique combination of high athermal stability, but lower thermal and optical (bleaching) stability of the pulsed $\mathbb{R}_{50}$ signal compared to the pIRIR signals. Since thermal stability is both a function of thermal trap depth and electron-hole distance (Jain et al, 2015b), it is expected that higher the thermal stability, the greater the fading stability. Thus, the pulsed $I_{50}$ signal should have exhibited the similar thermal stability as the pIRIR ${ }_{225}$ signal, but in fact, the thermal stability of the pulsed $I R_{50}$ signal was observed to be lower than that of the pIRIR ${ }_{225}$.

While further investigations are required, our data together with the data of Jain et al. (2015a), suggest that the pIRIR signals may be mobilising 'isolated' electrons (infinite tunnelling lifetime), which become available by diffusion and redistribution only at high temperature IR stimulations. Such isolated electrons will be thermally/athermally stable and difficult to bleach, and, thus, add a stable yet unbleachable component to the pIRIR signal. The pulsed $I_{50}$ on the other hand may sample a small component of a relatively stable electron population, which is just far enough from nearest holes to give an athermal stability on the geological time scales. Such electrons are likely to be less thermally stable and relatively easier to bleach compared to the 'isolated' electron population. Alternatively, there could possibly be a distribution in the trap depth of the IR trap. In this scenario, there will be a finite population of deep traps that will require a strong thermal assistance to be emptied and will be more difficult-to-bleach because of their higher optical depth; such traps may contaminate the pIRIR signals, but not the pulsed $I R_{50}$ signal since they will not be available at $50{ }^{\circ} \mathrm{C}$ measurement. $\mathrm{A}$ distribution in the trap depths is conceivable given the commonly observed disorder in feldspar crystals, however, this model further requires that there is no dependence of fading on the trap depth. Although, we incline towards the model of 'isolated' electrons, further research is required to fully understand the differences in the physical mechanisms behind pulsed $I_{50}$ and pIRIR signals.

Acknowledgements

We are very grateful to Torben Lapp who modified PTanalyse software; this made the analysis of the TR fading data much less time consuming. We would also like to thank Lars Pirtzel and Frank Oppermann who helped us to extend the on-gate delay. All participants of the HAZARD meeting 2016 in Wageningen are thanked for the active discussion on our results. Kyota Uemura and Takayuki Takahashi helped ST in the field in Sagamihara. Yan Li helped drawing the 3D TR plot. Technicians at LIAG are thanked for the sample preparation and gamma spectrometry measurements. 
References

Andersen, M.T., Jain, M., Tidemand-Lichtenberg, P. 2012. Red-IR stimulated luminescence in Kfeldspar: Single or multiple trap origin? Journal of Applied Physics, 112(4), 043507.

Balescu, S., Ritz, J-F., Lamothe, M., Auclair, M., Todbileg, M., 2007. Luminescence dating of a gigantic palaeolandslide in the Gobi-Altay mountains, Mongolia. Quaternary Geochronology 2, 290-295.

Buylaert, J.-P., Jain, M., Murray, A.S., Thomsen, K.J., Thiel, C., Sohbati, R., 2012. A robust feldspar luminescence dating method for Middle and Late Pleistocene sediments. Boreas 41, 435-451.

Colarossi, D., Duller, G.A.T., Roberts, H.M., Tooth, S., Lyons, R., 2015. Comparison of paired quartz and feldspar post-IR IRSL dose distributions in poorly bleached fluvial sediments from South Africa. Quaternary Geochronology 30, 233-238.

Dietmar, C. and Trier, M., 2006. Mit der U-Bahn in die Römerzeit. Ein Handbuch zu den archäologischen Ausgrabungsstätten rund um den Bau der Nord-Süd Stadtbahn. Köln, Germany: 245 p.

Hajdas, I, Zolitschka, B., Ivy-Ochs, S.D., Beer, J., Bonani, G., Leroy, S.A.G, Negendank, J.W., ramrath, M., Suter, M. 1995. AMS radiocarbon dating of annually laminated sediments from Lake Holzmaar, Germany. Quaternary Science Reviews 14, 137-143.

Huntley, D.J., Baril, M.R., 1997. The K content of the K-feldspars being measured in optical dating or in thermoluminescence dating. Ancient TL 15, 11-13.

Huntley, D.J., Lamothe, M., 2001. Ubiquity of anomalous fading in K-feldspars and the measurement and correction for it in optical dating. Canadian Journal of Earth Science 38, 1093-1106.

Kaizuka, S., Moriyama, A. 1969. Geomorphology and subsurface geology of the alluvial plain of the lower Sagami River, central Japan. Geographical Review of Japan 42, 85-105 (in Japanese with English abstract).

Jain, M., Ankjærgaard, C., 2011. Towards a non-fading signal in feldspar: insight into charge transport and tunnelling from time-resolved optically stimulated luminescence. Radiation Measurements 46, 292-309.

Jain, M., Buylaert, J.P., Thomsen, K.J., Murray, A.S. 2015a. Further investigations on 'non-fading ' in Kfeldspar. Quaternary International 362, 3-7.

Jain, M., Sohbati, R., Guralnik, B., Murray, A. S., Kook, M., Lapp, T., Prasad, A.K., Thomsen, K. and Buylaert, J. P. 2015b. Kinetics of infrared stimulated luminescence from feldspars. Radiation Measurements, 81, 242-250.

Jain, M., Guralnik, B., Andersen, M.T., 2012. Stimulated luminescence emission fromlocalized recombination in randomly distributed defects. Journal of Physics: Condensed Matter 24, 385402.

Kars, R.H., Reimann, T., Ankjærgaard, C., Wallinga, J. 2014. Bleaching of the post-IR IRSL signal: new insights for feldspar luminescence dating. Boreas 43, 780-791.

Kubo, S., 1997. Reconstruction of Paleo Sea-level and Landform Changes since the Marine Isotope Stage 5a, Using Buried Terraces in the Lower Sagami Plain, Central Japan. The Quaternary Research (Daiyonki Kenkyu) 36, 147-163 (in Japanese with English abstract).

Lapp, T., Jain, M., Ankjærgaard, C., Pirzel, L., 2009. Development of pulsed stimulation and photon timer attachments to the Risø TL/OSL reader. Radiation Measurements 44, 571-575.

Lauer, T., Bonn, R., Frechen, M., Fuchs, M.C., Trier, M., Tsukamoto, S. 2011a. Geoarchaeological studies on Roman time harbour sediments in Cologne - comparison of different OSL dating techniques. Geochronometria 38, 341-349.

Lauer, T., Frechen, M., Klostermann, J., Krbetschek, M., Schollmayer, G., Tsukamoto, S. 2011b. Luminescence dating of Last Glacial and Early Holocene fluvial deposits from the Lower Rhine methodological aspects and chronological framework. Zeitschrift der Deutschen Gesellschaft für Geowissenschaften 162, 47-61.

Lauer, T., Krbetschek, M., Mauz, B., Frechen, M. 2012. Yellow stimulated luminescence from potassium feldspar: Observations on its suitability for dating. Radiation Measurements 47, 974-980.

Li, B., Li, S.-H., 2011. Luminescence dating of K-feldspar from sediments: a protocol without anomalous fading correction. Quaternary Geochronology 6, 468-479.

Miallier, D., Sanzelle, S., Fain, J. 1983. The use of flotation techniques to separate quartz from feldspar. Ancient TL 1, 5-6. 
Miyairi, Y., Yoshida, K., Miyazaki, Y., Matsuzaki, H., Kaneoka, I. 2004. Improved ${ }^{14} \mathrm{C}$ dating of a tephra layer (AT tephra, Japan) using AMS radiocarbon on selected organic fractions. Nuclear Instruments and Method in Physics Research B 223/224, 555-559.

Pagonis, V., Phan, H., Goodnow, R., Rosenfeld, S., Morthekai, P. 2014. Mathematical characterization of continuous wave infrared stimulated luminescence signals (CW-IRSL) from feldspars. Journal of Luminescence, 154, 362-368.

Reimann, T., Tsukamoto, S. 2012. Dating the recent past ( $<500$ years) by post-IR IRSL feldspar Examples from the North Sea and Baltic Sea coast. Quaternary Geochronology, 10, 180-187.

Research Group of Geomorphology and Geology in Sagamihara (Machida, H., Moriwaki, H., Takahashi, M., Kubo, S., Yoshinaga, S.), 1984. Report of geomorphological and geological investigations in Sagamihara. Sagamihara-city, 57p (in Japanese).

Roskosch, J., Winsemann, J., Polom, U., Brandes, C., Tsukamoto, S., Weitkamp, A., Bartholomäus, W., Henningsen, D., Frechen, M. 2015a. Luminescence dating of ice-marginal deposits in northern Germany: evidence for repeated glaciations during the Middle Pleistocene (MIS 12 to MIS 6). Boreas, 44, 103-126.

Roskosch, J., Tsukamoto, S., Frechen, M. 2015b. Luminescence dating of fluvial deposits from the Weser valley, Germany. Geochronometria, 42, 126-138.

Sanderson, D.C.W., Clark, R.J., 1994. Pulsed photostimulated luminescence of alkali feldspars. Radiation Measurements 23, 633-639.

Smith, V.C., Staff, R.A., Blockley, S.P.E., Bronk Ramsey, C., Nakagawa, T., Mark, D.F., Takemura, K., Danhara, T., Suigetsu 2006 Project Members, 2013. Identification and correlation of visible tephras in the Lake Suigetsu SG06 sedimentary archive, Japan: chronostratigraphic markers for synchronising of east Asian/west Pacific palaeoclimatic records across the last $150 \mathrm{ka}$. Quaternary Science Reviews 67, 121-137.

Thomsen, K.J., Murray, A.S., Jain, M., Bøtter-Jensen, L., 2008. Laboratory fading rates of various luminescence signals from feldspar-rich sediment extracts. Radiation Measurements 43, 14741486.

Thomsen, K.J., Murray, A.S., Jain, M., 2011. Stability of IRSL signals from sedimentary K-feldspar samples. Geochronometria 38, 1-13.

Tsukamoto, S., Denby, P.M., Murray, A.S., Bøtter-Jensen, L., 2006. Time-resolved luminescence from feldspars: new insight into fading. Radiation Measurements 41, 790-795.

Van den Bogaard, P. 1995. 40Ar/39Ar ages of sanidine phenocrysts from Laacher See Tephra $(12,900$ yr BP): chronostratigraphic and petrological significance. Earth and Planetary Science Letters 133, 163-174.

Zhang, J., Tsukamoto, S., Nottebaum, V., Lehmkuhl, F., Frechen, M. 2015. De plateau and its implications for post-IR IRSL dating of polymineral fine grains. Quaternary Geochronology, 30, 147-153. 
Figure captions

Fig. 1: Map showing the locations of sampling sites at (a) Cologne and Monheim, Germany and (b) Sagamihara, Japan. Geomorphological maps were modified from Lauer et al. (2011b) and from Kubo (1997). Insets show the location of the detailed map.

Fig. 2: Graphic sedimentary logs of sampling sites at (a) Cologne, (b) Monheim and (c) Sagamihara.

Fig. 3: (a) 3D time resolved (TR) IRSL curve of MHT-II measured at $50^{\circ} \mathrm{C}$ for $500 \mathrm{~s}$ with $100 \mu \mathrm{s}$ on and $400 \mu \mathrm{s}$ off, after irradiating $40 \mathrm{~Gy}$ and preheating at $250^{\circ} \mathrm{C}$ for $60 \mathrm{~s}$. (b) photon arrival time curve from the same dataset, (c) IRSL decay curve for on-time and off-time from the TR measurement showing in (a). (d) Normalised on- and off-time decay curves. Note that the X-axis of the decay curve was adjusted to the on-time (500 s pulsed $I_{50}$ measurement $=100 \mathrm{~s}$ on-time).

Fig. 4: Bleaching curves of $I R_{50}$ (pre-pIR 225 ), $I R_{50}$ (pre-pIR 290 ), pIRIR 225 , pIRIR 290 and pulsed $I R_{50}$ signals for (a) MHT-II and (b) LUM-3291 for the initial signal (0-4s). The data for MHT-II were also plotted for the different signal integration limits, 0-4s, 4-12s, 12-20s, and 20-40s for (c) $I_{50}$ (pre-pIR 225 ) and pIRIR $R_{225}$ and for (d) pulsed $I R_{50}$. Note that the integration period for the pulsed $I_{50}$ signal is showed on its ontime.

Fig. 5: (a) Anomalous fading of $I R_{50}$ (pre-pIR 225 ), IR $R_{50}$ (pre-pIR 290 ), pIRIR 225 , pIRIR 290 and pulsed $I R_{50}$ signals for all samples using the initial (0-4s) signal. The g-values of these signals calculated from the different signal integration limits (0-4s, 4-12s, 12-20s and 20-40s) are plotted for (b) SW-II, (c) MHT-II and (d) LUM-3291.

Fig. 6: Fading rate ( $\mathrm{g}_{2 \text { days }}$-value) measured by TR-IRSL for MHT-II. Data are plotted with two different integration limits, $0-4 \mathrm{~s}$ and $4-12 \mathrm{~s}$ of the decay curve.

Fig. 7: Thermal stability of the $\mid R_{50}$ (pre-pIR $R_{225}$ ), pIRIR $R_{225}$ and pulsed $I R_{50}$ signals for (a) $0-4 s$ signal integration. (b) The same dataset as (a) for four different signal integration limits.

Fig. 8: (a) Dose recovery ratio and (b) measured residual dose after $4 \mathrm{~h}$ bleaching with a solar simulator for $I R_{50}$ (pre-pIR 225 ), IR $R_{50}$ (pre-pIR 290 ), pIRIR 225 , pIRIR 290 and pulsed $I R_{50}$ signals. 
1 Fig. 9: Comparison of the pIRIR 225 , pIRIR 290 , pulsed $I_{50}$ ages and with independent age control. The 2 luminescence ages were plotted against the mean quartz ages for SW-II and MHT-II and against the 3 tephra (AT) age for LUM-3291. 
Table 1: Age control information for the studied samples.

\begin{tabular}{|c|c|c|c|c|c|c|}
\hline \multirow{3}{*}{ Site } & \multirow{3}{*}{ Sample code } & \multirow{3}{*}{ Description of age control } & \multicolumn{3}{|c|}{ Age control } & \multirow{3}{*}{ Reference } \\
\hline & & & \multicolumn{2}{|r|}{ Radiocarbon } & \multirow[t]{2}{*}{ Other } & \\
\hline & & & ${ }^{14} \mathrm{CBP}$ & Calibrated (cal BP)* & & \\
\hline \multirow[t]{5}{*}{ Cologne subway } & SW-II & quartz OSL of the same sample & & & $3460 \pm 350$ (mean), $1980 \pm 330$ (MAM3) & Lauer et al. (2011a) \\
\hline & SW-I & quartz OSL, $5 \mathrm{~m}$ west of SW-II & & & $2220 \pm 170$ (mean post-IR OSL) & Lauer et al. (2011a) \\
\hline & RC-1 & ${ }^{14} \mathrm{C}$ of charcoal, above SW-II & $2010 \pm 55$ & $1832-1842(1 \%), 1864-2119(99 \%)$ & & Lauer et al. (2011a) \\
\hline & RC-2 & ${ }^{14} \mathrm{C}$ of charcoal, below SW-II & $2080 \pm 85$ & $1876-2211(88 \%), 2221-2308(12 \%)$ & & Lauer et al. (2011a) \\
\hline & RC-3 & ${ }^{14} \mathrm{C}$ of charcoal, below SW-II & $2025 \pm 60$ & $1865-2145(100 \%)$ & & Lauer et al. (2011a) \\
\hline \multirow[t]{6}{*}{ Monheim } & MHT-II & quartz OSL of the same sample & & & $11.6 \pm 0.7 \mathrm{ka}$ & Lauer et al. (2011b) \\
\hline & MHT-I & quartz OSL, $4 \mathrm{~m}$ below & & & $11.7 \pm 1.0 \mathrm{ka}$ & Lauer et al. (2011b) \\
\hline & MHT-III & quartz OSL, $1.5 \mathrm{~m}$ above & & & $11.6 \pm 1.3 \mathrm{ka}$ & Lauer et al. (2011b) \\
\hline & HYM-13a & $\begin{array}{l}{ }^{14} \mathrm{C} \text { of macrofossil from Holzmaar at the } \\
\text { position of Laacher See tephra }\end{array}$ & $11210 \pm 95$ & $12830-13266(100 \%)$ & & Hadjas et al. (1995) \\
\hline & HYM-13b & $\begin{array}{l}{ }^{14} \mathrm{C} \text { of macrofossil from Holzmaar at the } \\
\text { position of Laacher See tephra }\end{array}$ & $11380 \pm 95$ & $13071-13413(100 \%)$ & & Hadjas et al. (1995) \\
\hline & & $\mathrm{Ar} / \mathrm{Ar}$ of sanidine from Laacher See Tephra & & & $12.90 \pm 0.56 \mathrm{ka}$ & van den Vogaard (1995) \\
\hline \multirow[t]{2}{*}{ Sagamihara } & & $\begin{array}{l}{ }^{14} \mathrm{C} \text { of charcoal and humic acid for Aira } \\
\text { Tanzawa (AT) tephra, } 40 \mathrm{~cm} \text { above } \\
\text { Varve chronology combined with }\end{array}$ & $25,120 \pm 270 \mathrm{BP}$ & 28577 - 29831 (100\%) & & Miyairi et al. (2004) \\
\hline & & $\begin{array}{l}\text { macrofossil }{ }^{14} \mathrm{C} \text { in Lake Suigetsu, } 15 \mathrm{~cm} \\
\text { above }\end{array}$ & & $30,009 \pm 189$ & & Smith et al. (2013) \\
\hline
\end{tabular}

*All radiocarbon ages are recalibrated using Intcal 13. 
Table 2: pIRIR 225 , pIRIR 290 and pulsed IR 50 protocols, used in this study.

\begin{tabular}{|c|c|c|c|c|c|c|c|c|}
\hline \multirow{2}{*}{$\frac{a}{\text { Step }}$} & \multicolumn{2}{|c|}{$\mathrm{pIRIR}_{225}$} & \multirow{2}{*}{$\frac{\mathrm{b}}{\text { Step }}$} & \multicolumn{2}{|c|}{$p|R| R_{290}$} & \multirow{2}{*}{$\begin{array}{c}\text { c } \\
\text { Step }\end{array}$} & \multicolumn{2}{|l|}{ pulsed $I_{50}$} \\
\hline & Treatment & Observed & & Treatment & Observed & & Treatment & Observed \\
\hline 1 & Dose & & 1 & Dose & & 1 & Dose & \\
\hline 2 & Preheat $250^{\circ} \mathrm{C} 60 \mathrm{~s}$ & & 2 & Preheat $320^{\circ} \mathrm{C} 60 \mathrm{~s}$ & & 2 & Preheat $250^{\circ} \mathrm{C} 60 \mathrm{~s}$ & \\
\hline 3 & IRSL $50^{\circ} \mathrm{C} 100 \mathrm{~s}$ & $L x$ & 3 & IRSL $50^{\circ} \mathrm{C} 100 \mathrm{~s}$ & & 3 & Pulsed IRSL $50^{\circ} \mathrm{C}$ for $500 \mathrm{~s}^{*}$ & $L x$ \\
\hline 4 & pIRIR $225^{\circ} \mathrm{C} 200 \mathrm{~s}$ & $L x$ & 4 & pIRIR $290^{\circ} \mathrm{C} 200 \mathrm{~s}$ & $L x$ & 4 & Test Dose & \\
\hline 5 & Test Dose & & 5 & Test Dose & & 5 & Preheat $250^{\circ} \mathrm{C} 60 \mathrm{~s}$ & \\
\hline 6 & Preheat $250^{\circ} \mathrm{C} 60 \mathrm{~s}$ & & 6 & Preheat $320^{\circ} \mathrm{C} 60 \mathrm{~s}$ & & 6 & Pulsed IRSL $50^{\circ} \mathrm{C}$ for $500 \mathrm{~s}^{*}$ & Tx \\
\hline 7 & IRSL $50^{\circ} \mathrm{C} 100 \mathrm{~s}$ & Tx & 7 & IRSL $50^{\circ} \mathrm{C} 100 \mathrm{~s}$ & & 7 & Back to 1 & \\
\hline 8 & pIRIR $225^{\circ} \mathrm{C} 200 \mathrm{~s}$ & Tx & 8 & pIRIR $290^{\circ} \mathrm{C} 200 \mathrm{~s}$ & Tx & & & \\
\hline 9 & Back to 1 & & & Back to 1 & & & & \\
\hline
\end{tabular}

* $100 \mu$ s on and $400 \mu$ s off (total on time: 100 s) 
Table 3: Dose rate, $D_{\mathrm{e}}$ values, fading rate and age of the samples.

\begin{tabular}{|c|c|c|c|c|c|c|c|c|c|c|c|c|c|}
\hline \multirow{2}{*}{$\frac{\text { Sample }}{\text { SW-II }}$} & \multicolumn{2}{|c|}{ Dose rate (Gy/ka) } & \multirow{2}{*}{$\begin{array}{l}\text { Signal } \\
\text { pIRIR }_{225}\end{array}$} & \multicolumn{3}{|c|}{$D_{e}(G y)$} & \multicolumn{3}{|c|}{$\begin{array}{c}\text { g-value } \\
\text { (\%/decade) }\end{array}$} & \multicolumn{2}{|c|}{$\begin{array}{c}\text { Fading uncorrected } \\
\text { age (ka) }\end{array}$} & \multicolumn{2}{|c|}{$\begin{array}{l}\text { Fading corrected } \\
\text { age (ka) }\end{array}$} \\
\hline & 2.81 & \pm 0.13 & & 16.5 & \pm & 0.7 & 2.1 & \pm & 0.3 & $5.9 \pm$ & 0.4 & $6.9 \pm$ & 0.4 \\
\hline & & & $\mathrm{pIRIR}_{290}$ & 30.8 & \pm & 1.1 & 1.8 & \pm & 0.1 & $11.0 \pm$ & 0.7 & $12.8 \pm$ & 0.8 \\
\hline & & & pulsed $I R_{50}$ & 9.9 & \pm & 1.0 & 0.6 & \pm & 0.3 & $3.5 \pm$ & 0.4 & $3.7 \pm$ & 0.4 \\
\hline \multirow[t]{3}{*}{ MHT-II } & 2.88 & $\pm \quad 0.13$ & $\mathrm{pIRIR}_{225}$ & 40.3 & \pm & 1.4 & 2.2 & \pm & 0.3 & $14.0 \pm$ & 0.8 & $17.3 \pm$ & 1.1 \\
\hline & & & $\mathrm{pIRIR}_{290}$ & 57.3 & \pm & 1.4 & 1.7 & \pm & 0.5 & $19.9 \pm$ & 1.1 & $23.3 \pm$ & 1.7 \\
\hline & & & pulsed $I_{50}$ & 27.9 & \pm & 0.9 & 1.6 & \pm & 0.3 & $9.7 \pm$ & 0.6 & $11.1 \pm$ & 0.7 \\
\hline \multirow[t]{3}{*}{ LUM-3291 } & 1.52 & $\pm \quad 0.12$ & $\mathrm{pIRIR}_{225}$ & 147 & \pm & 13 & 0.5 & \pm & 0.3 & $96.2 \pm$ & 11.5 & $101 \pm$ & 12 \\
\hline & & & $\mathrm{pIRIR}_{290}$ & 164 & \pm & 14 & 0.05 & \pm & 0.5 & $107 \pm$ & 13 & n.a. & \\
\hline & & & pulsed $I_{50}$ & 51.5 & \pm & 2.4 & -0.8 & \pm & 0.5 & $33.8 \pm$ & 2.2 & n.a. & \\
\hline
\end{tabular}


(a)

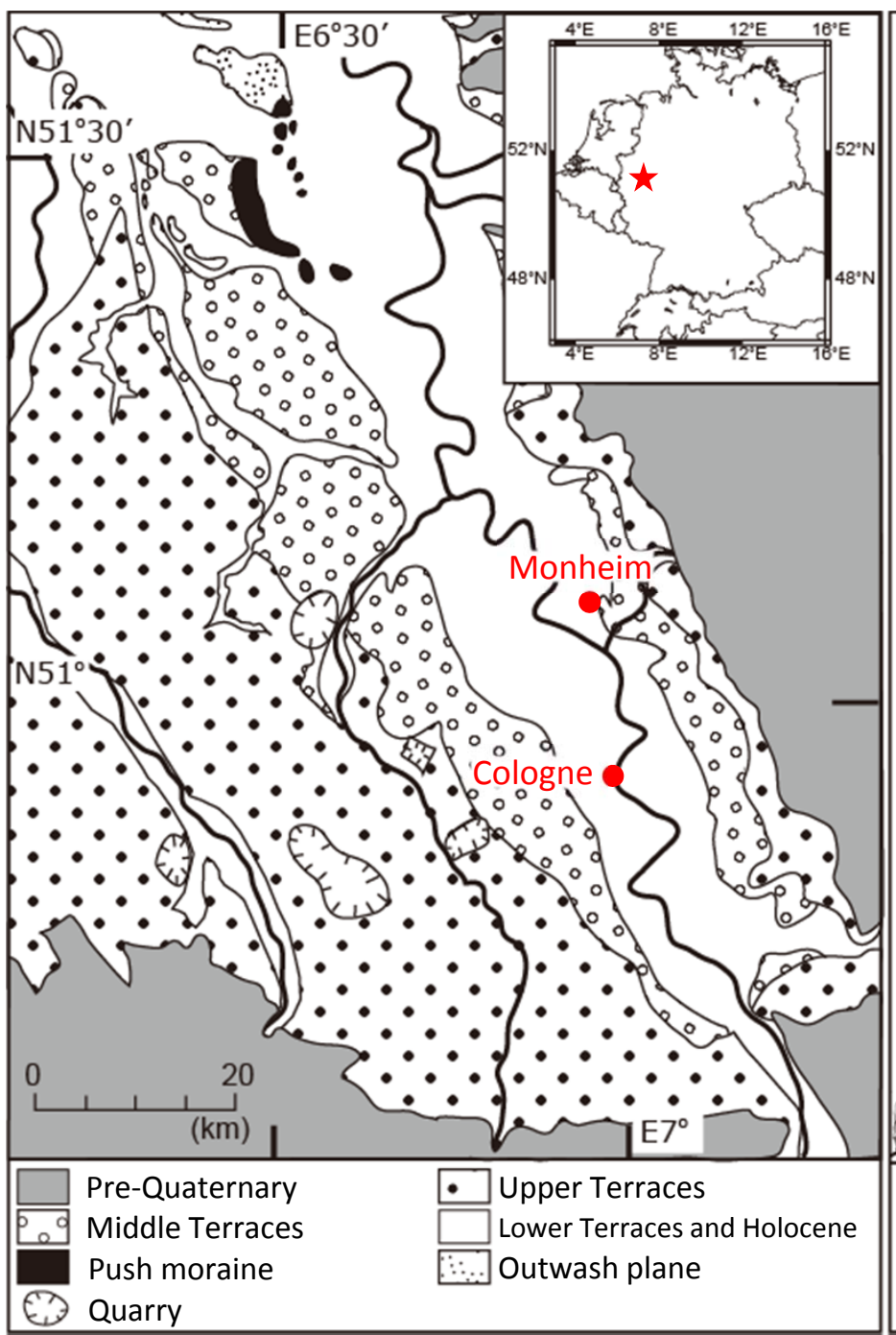

(b)

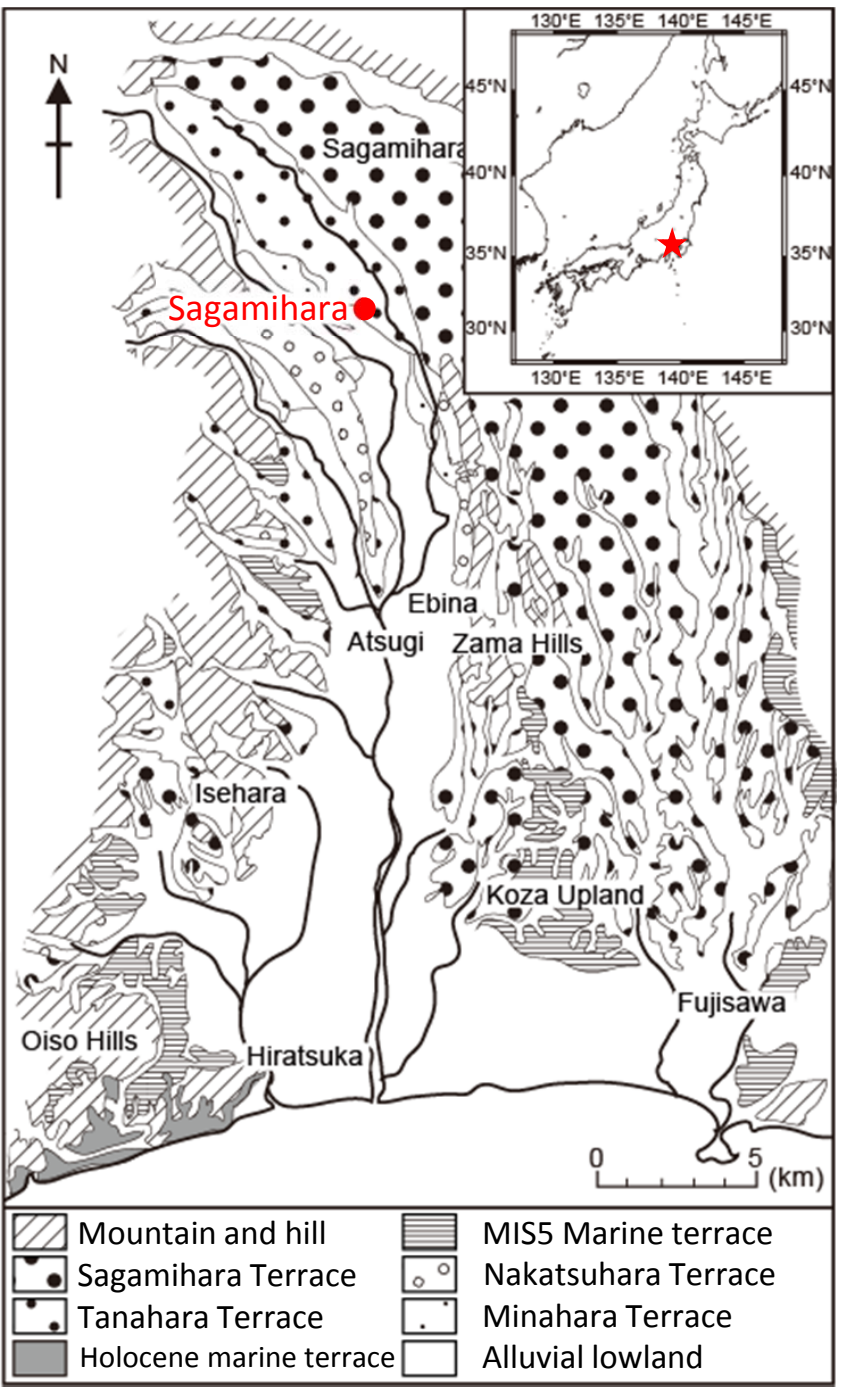

Fig. 1 

(m) (a) Cologne
(b) Monheim
(c) Sagamihara
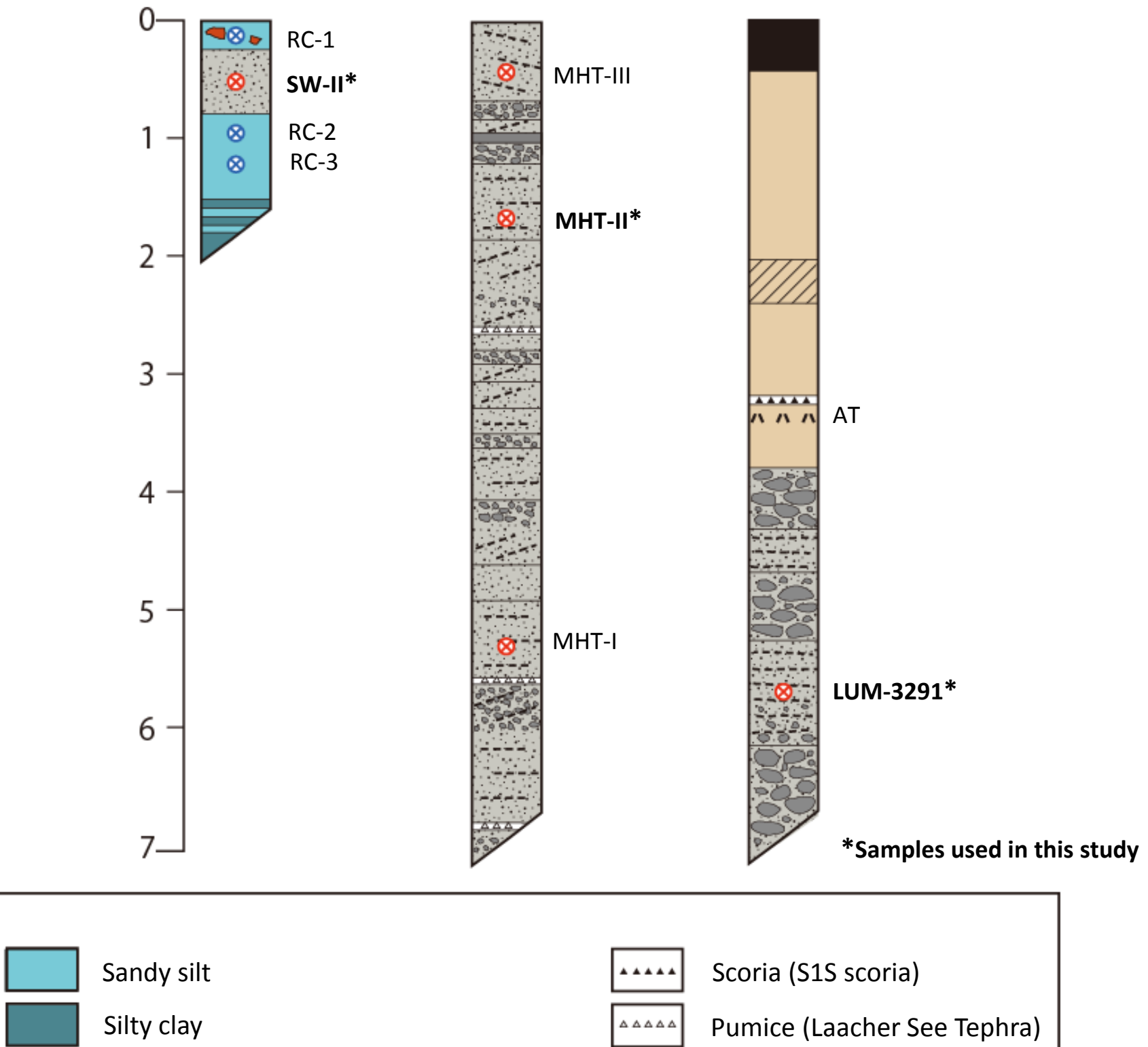

Sandy silt

A.4. Scoria (S1S scoria)

Silty clay

$\Delta \Delta \Delta \Delta \Delta$ Pumice (Laacher See Tephra)

Andosol

^ハ Volcanic ash (AT Tephra)

Clay

---- Holizontally stratified bed

Aeolian sand and silt (tephric loess)

..- Cross stratified bed

Dark coloured band

$\infty$ Brick

Fluvial sand

$\otimes$ Luminescence sample

Gravel

( $\quad$ Radiocarbon sample

Fig. 2 
(a)

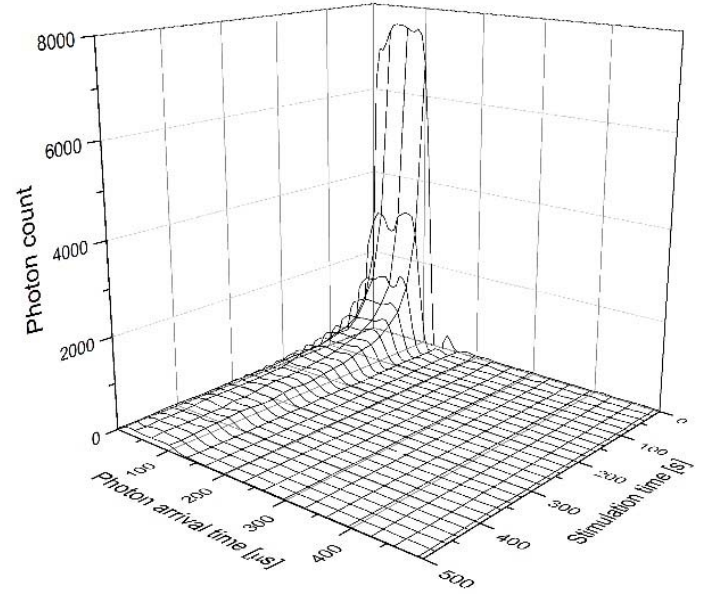

(c)

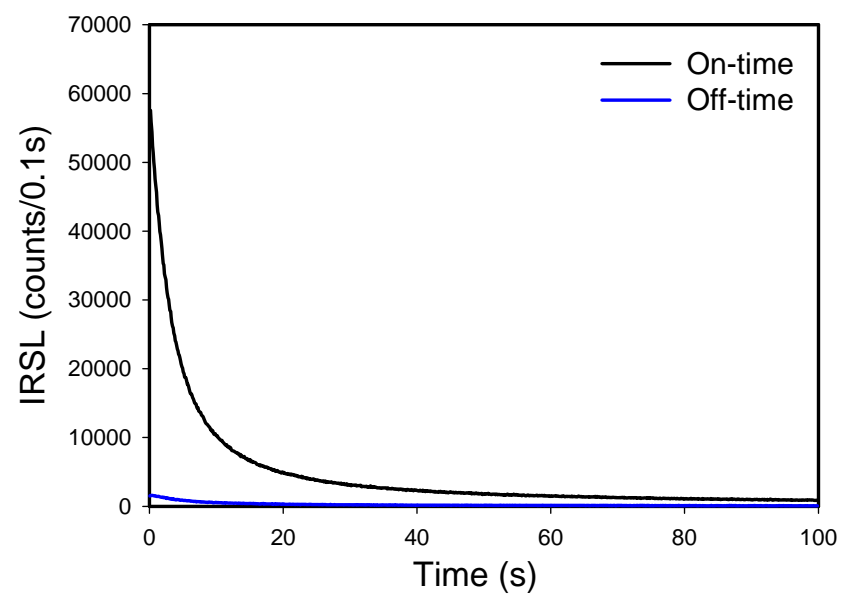

(b)

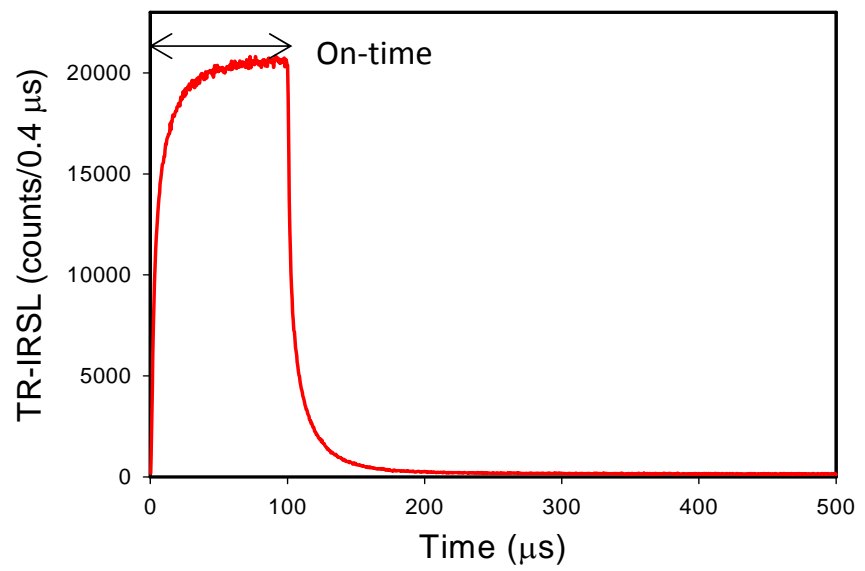

(d)

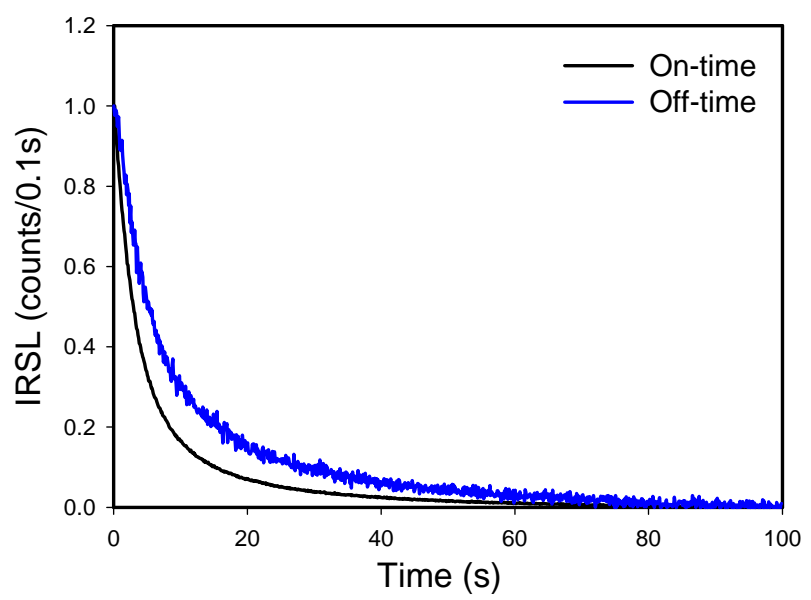

Fig. 3 
(a) MHT-II

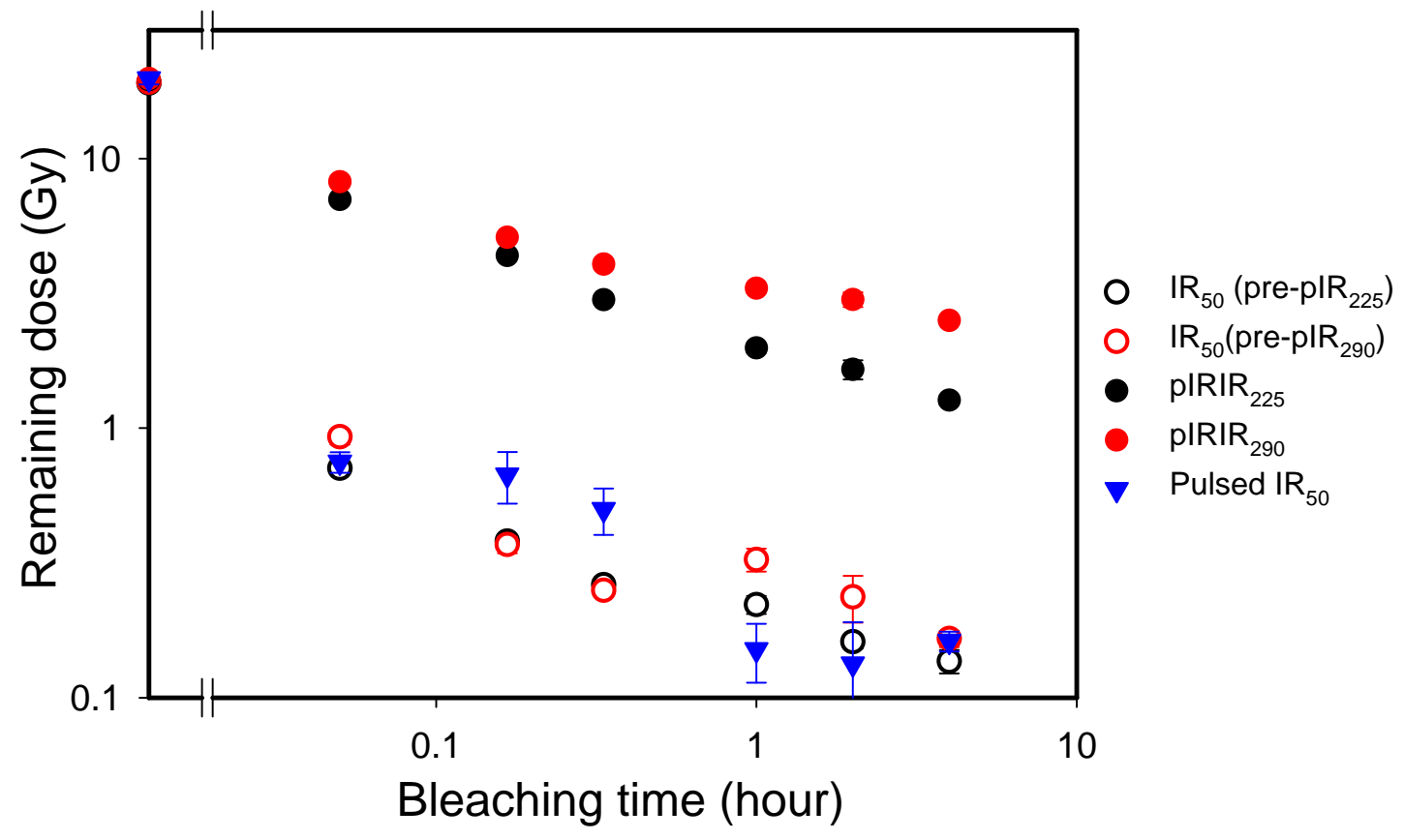

(b) LUM-3291

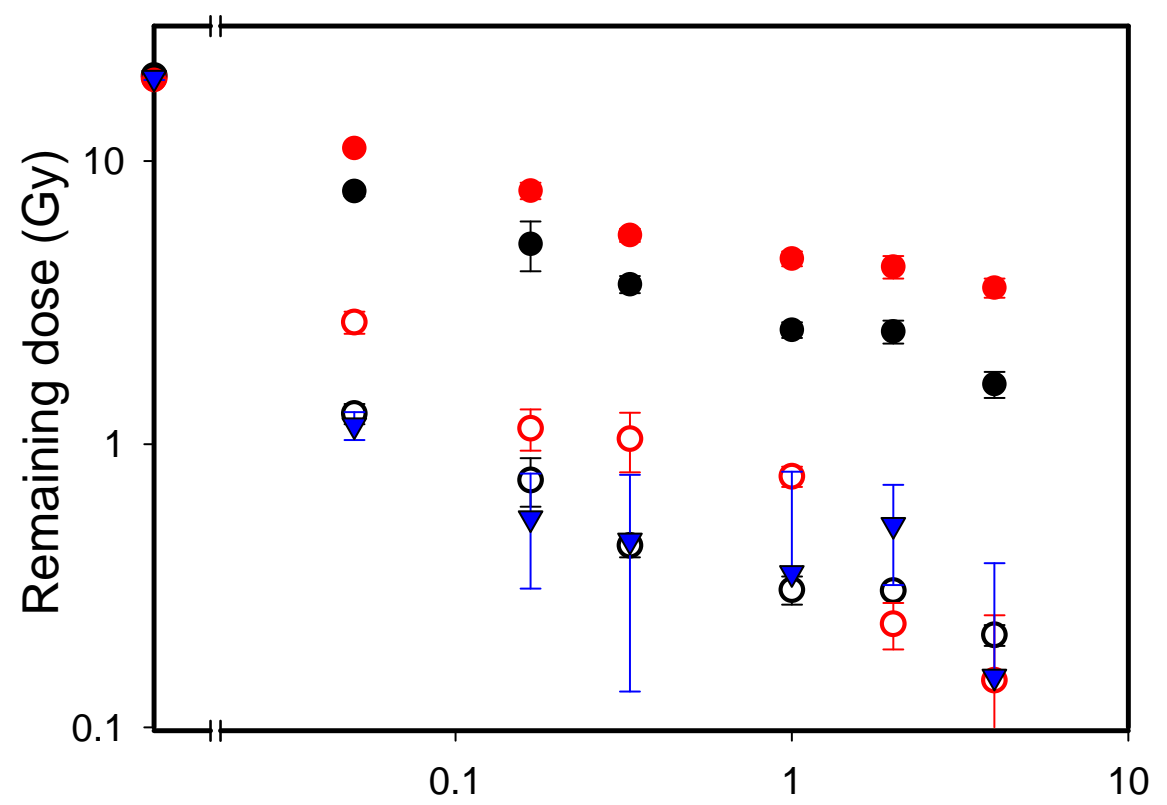

Bleaching time (hour)

Fig. 4 
(c)

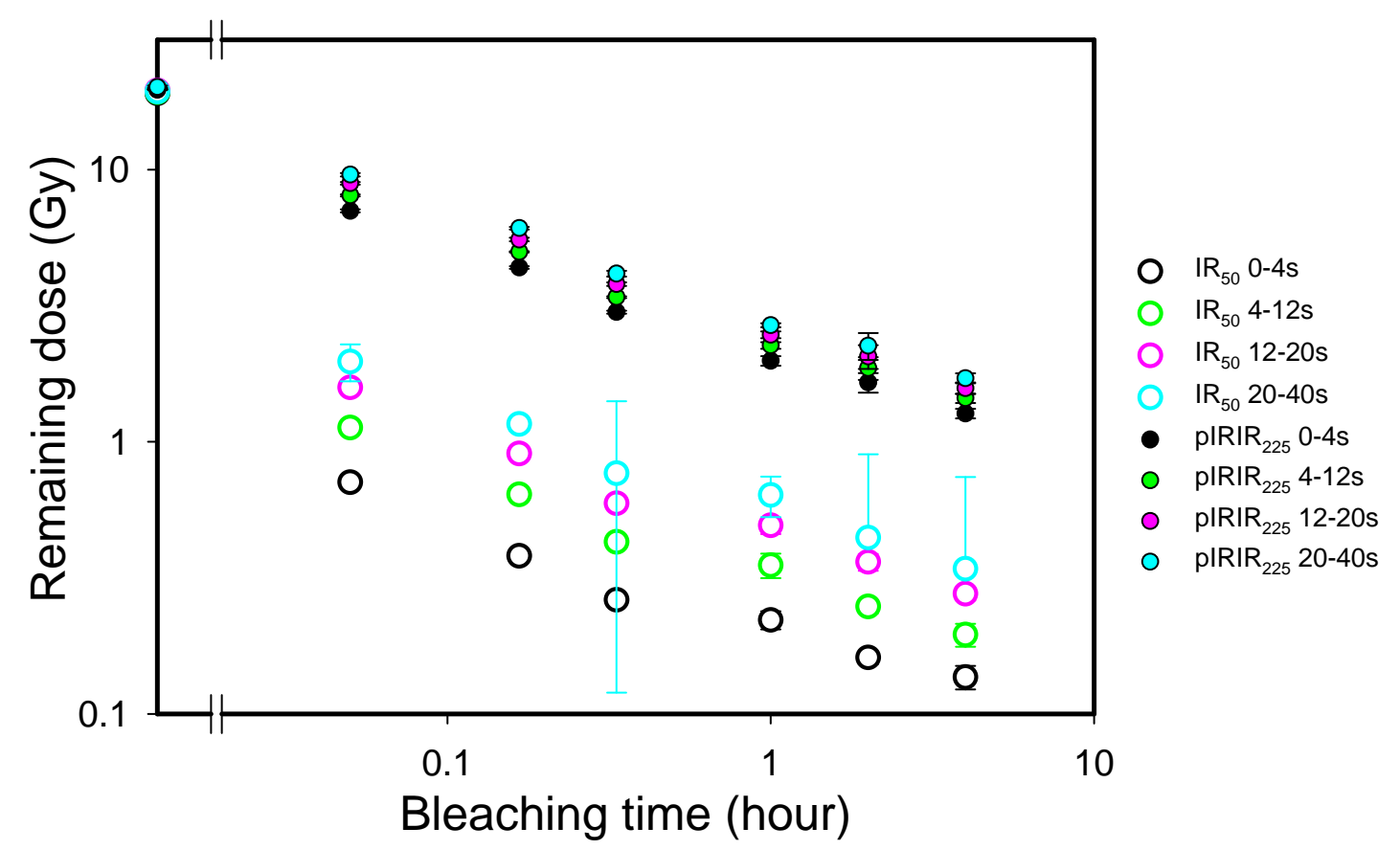

(d)

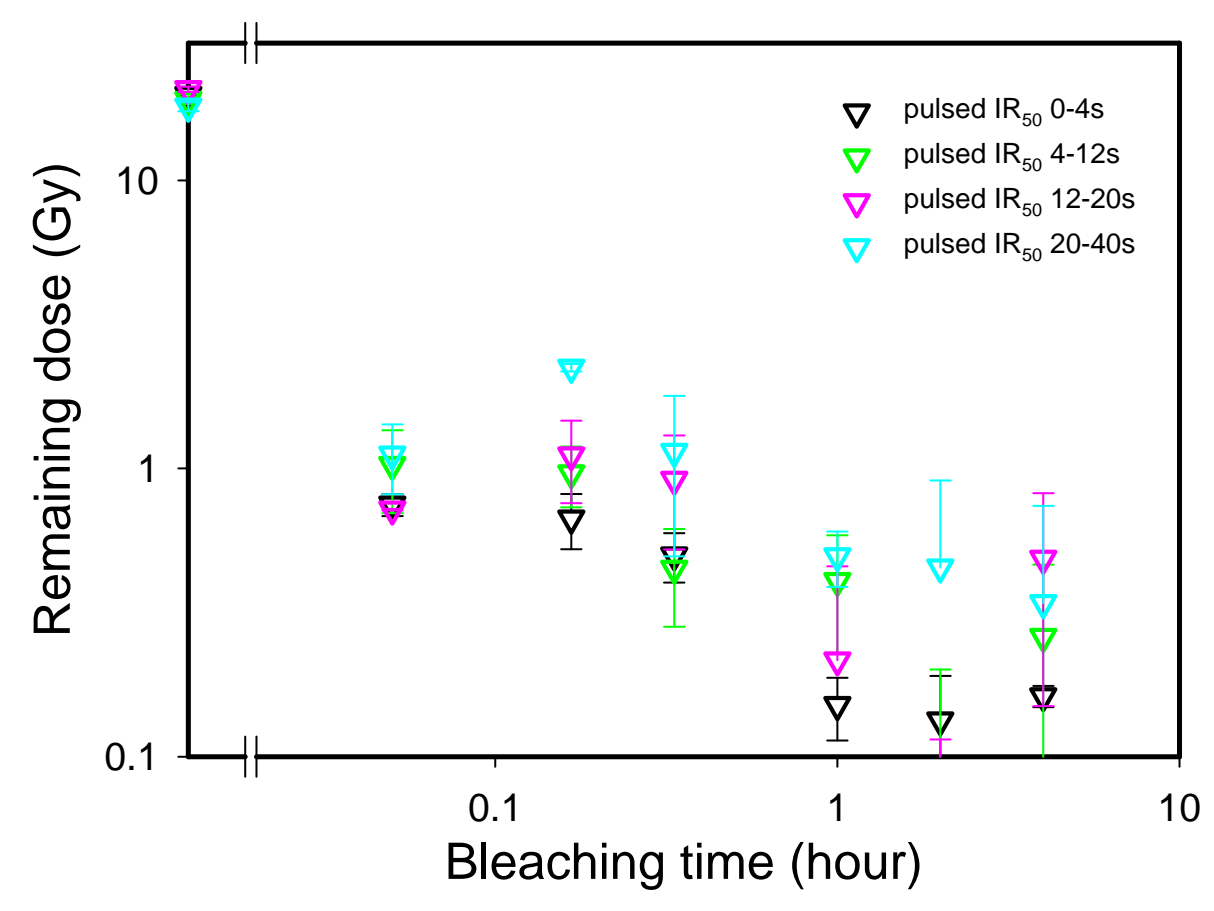

Fig. 4 (continued) 
(a)

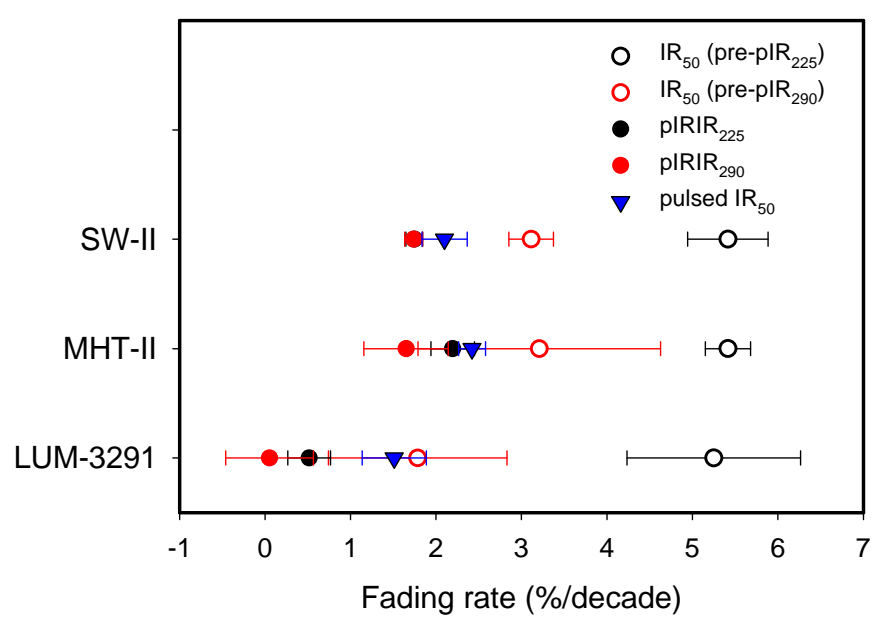

(c) MHT-II

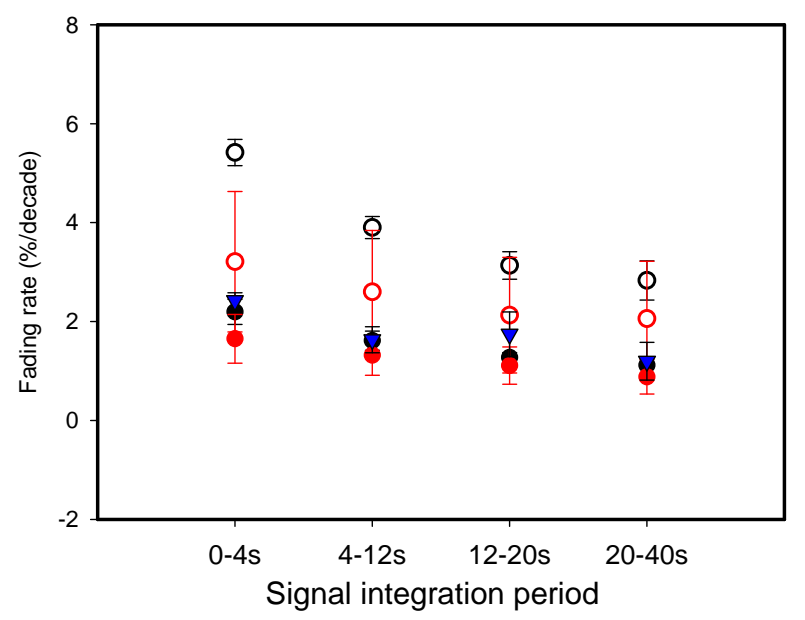

(b) SW-II

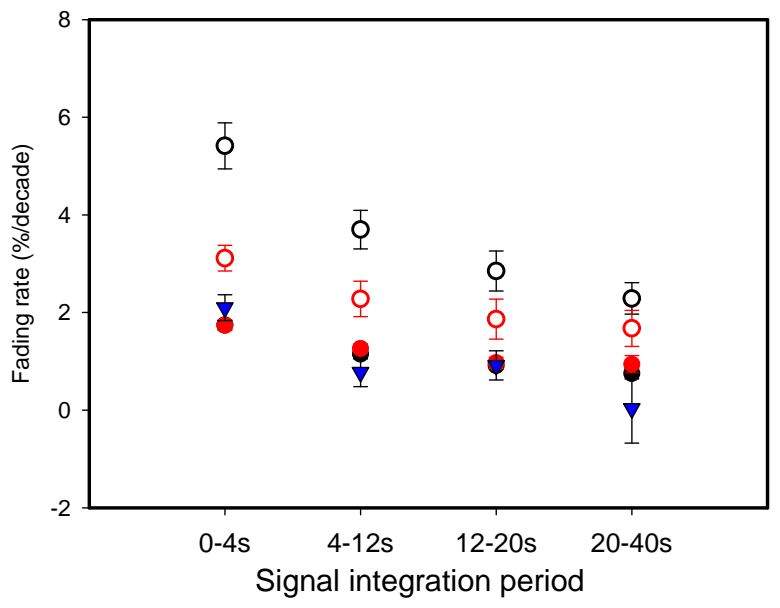

(d) LUM-3291

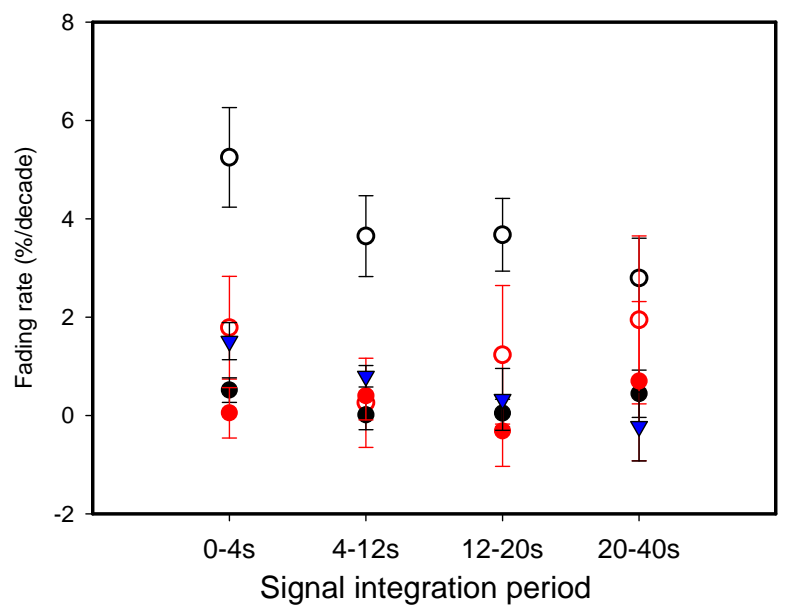

Fig. 5 


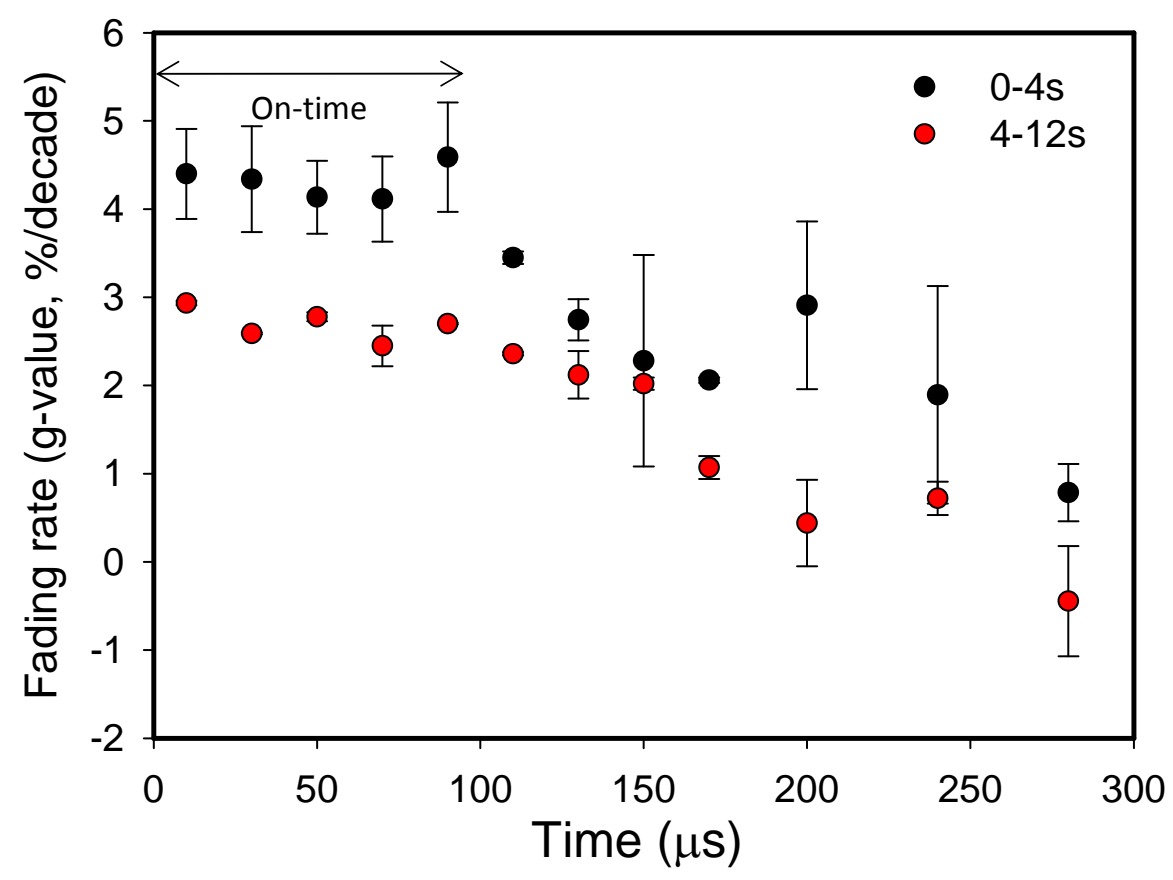

Fig. 6 
(a)

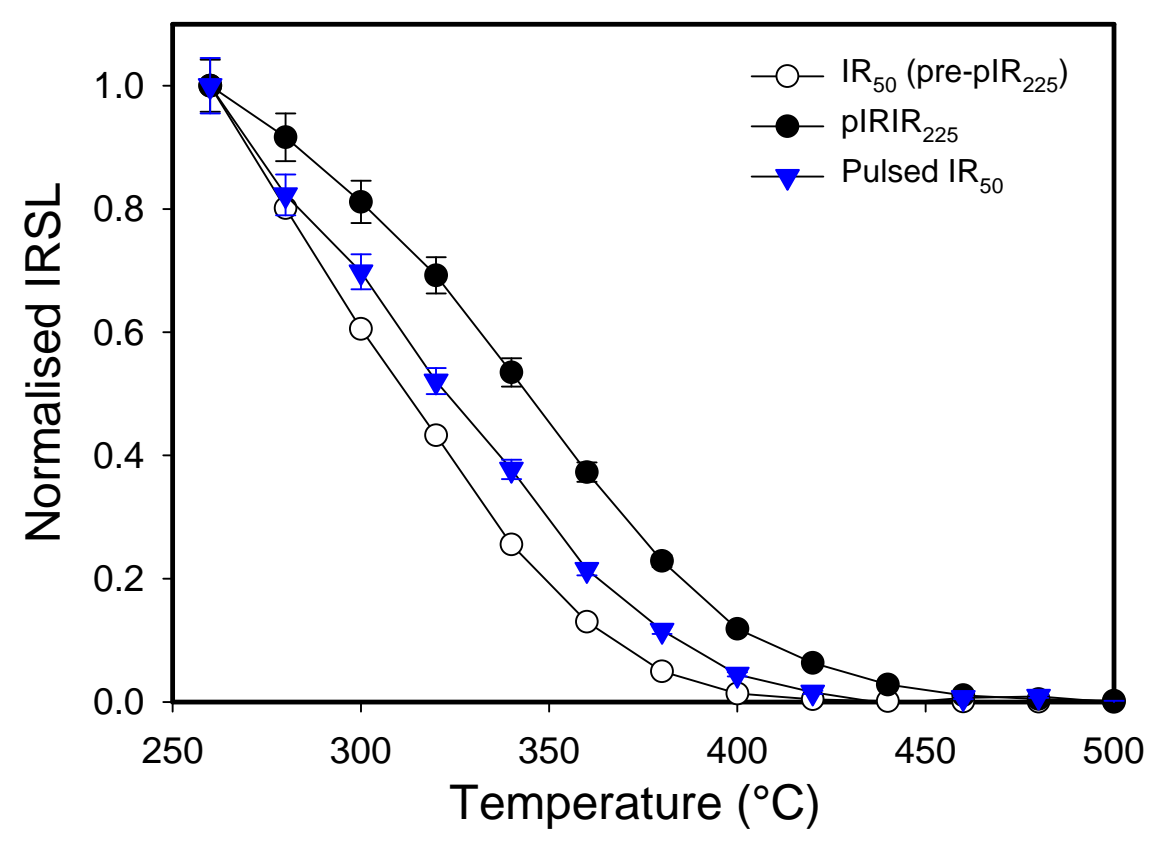

(b)

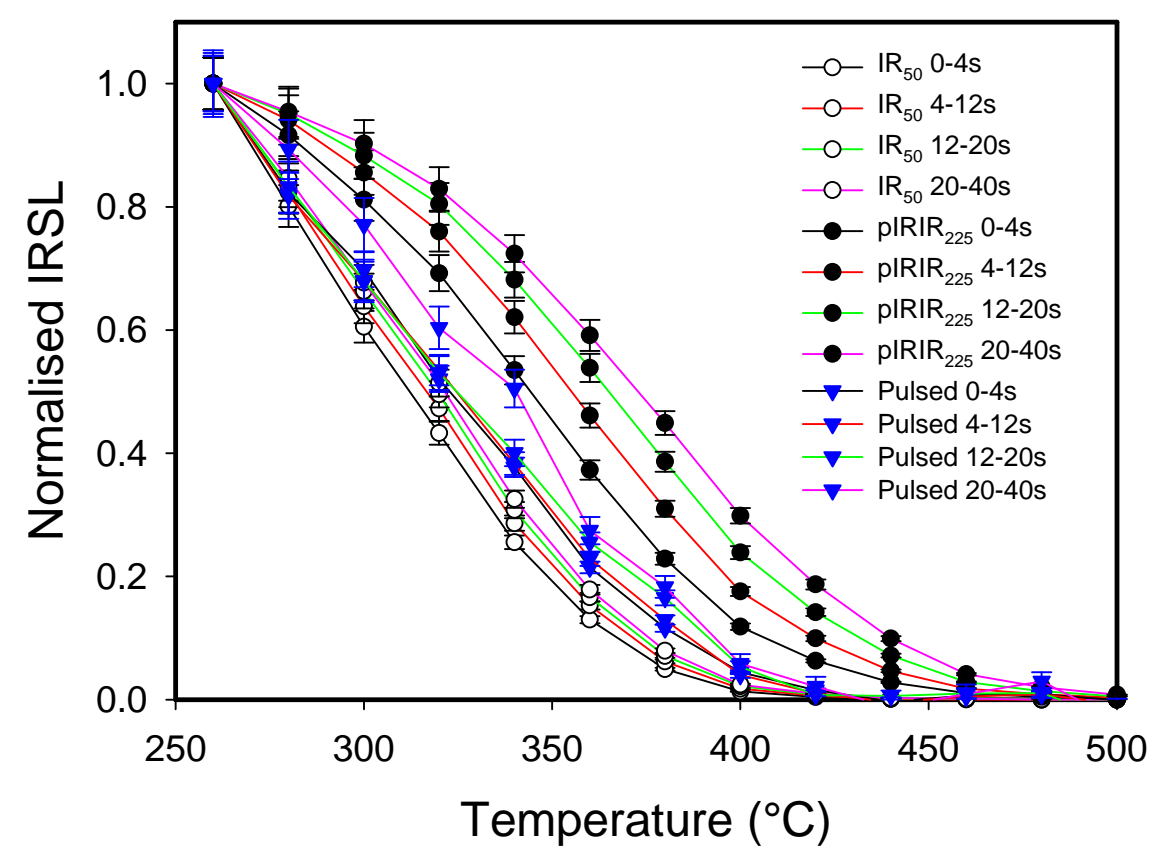

Fig. 7 
(a)

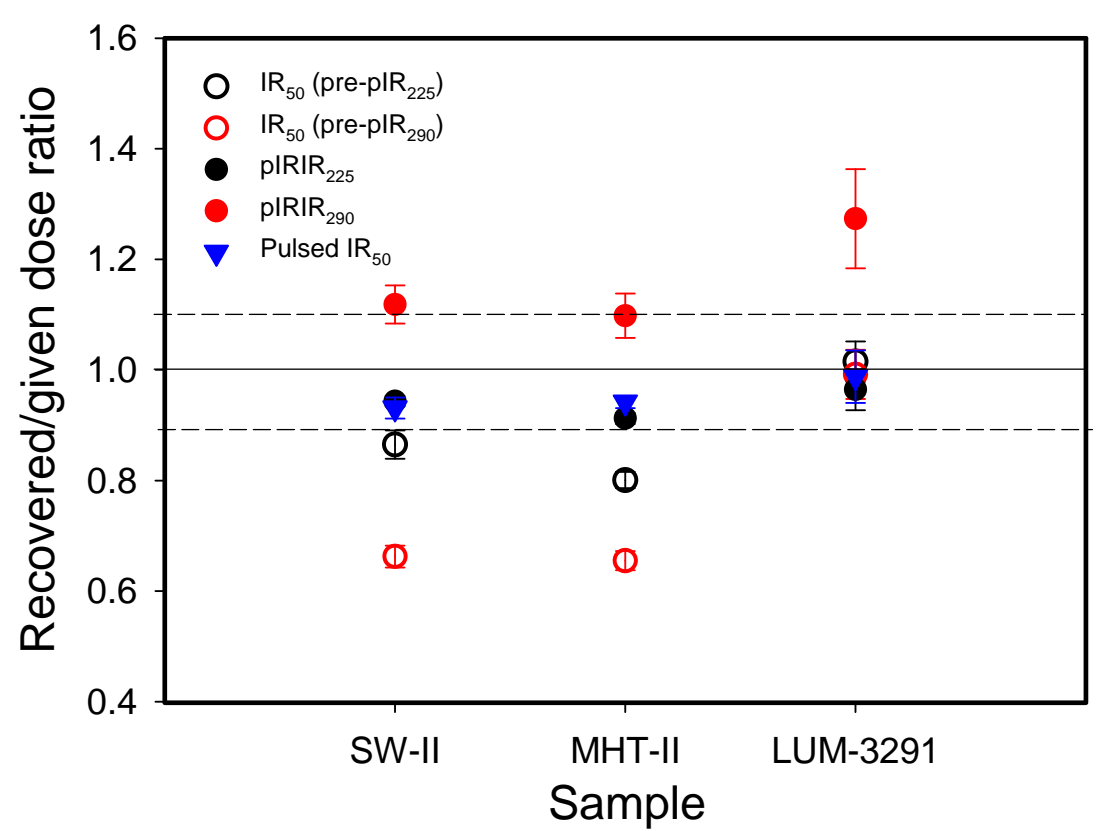

(b)

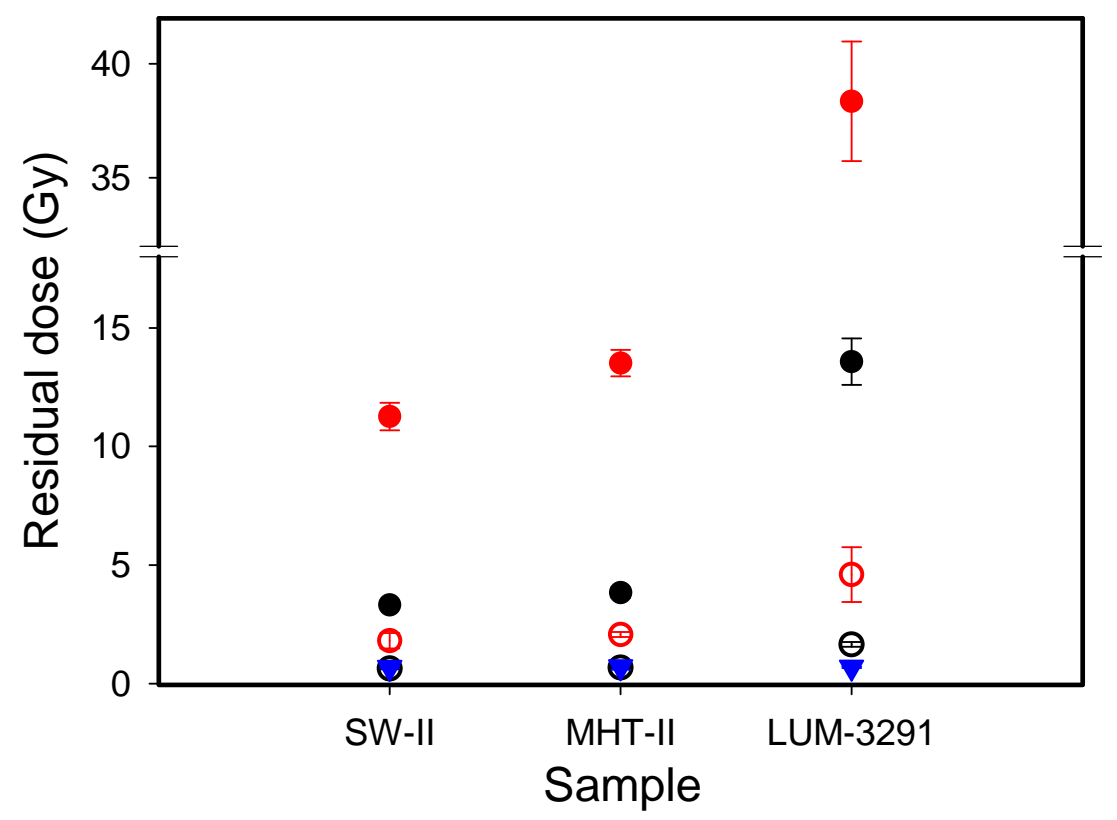

Fig. 8 


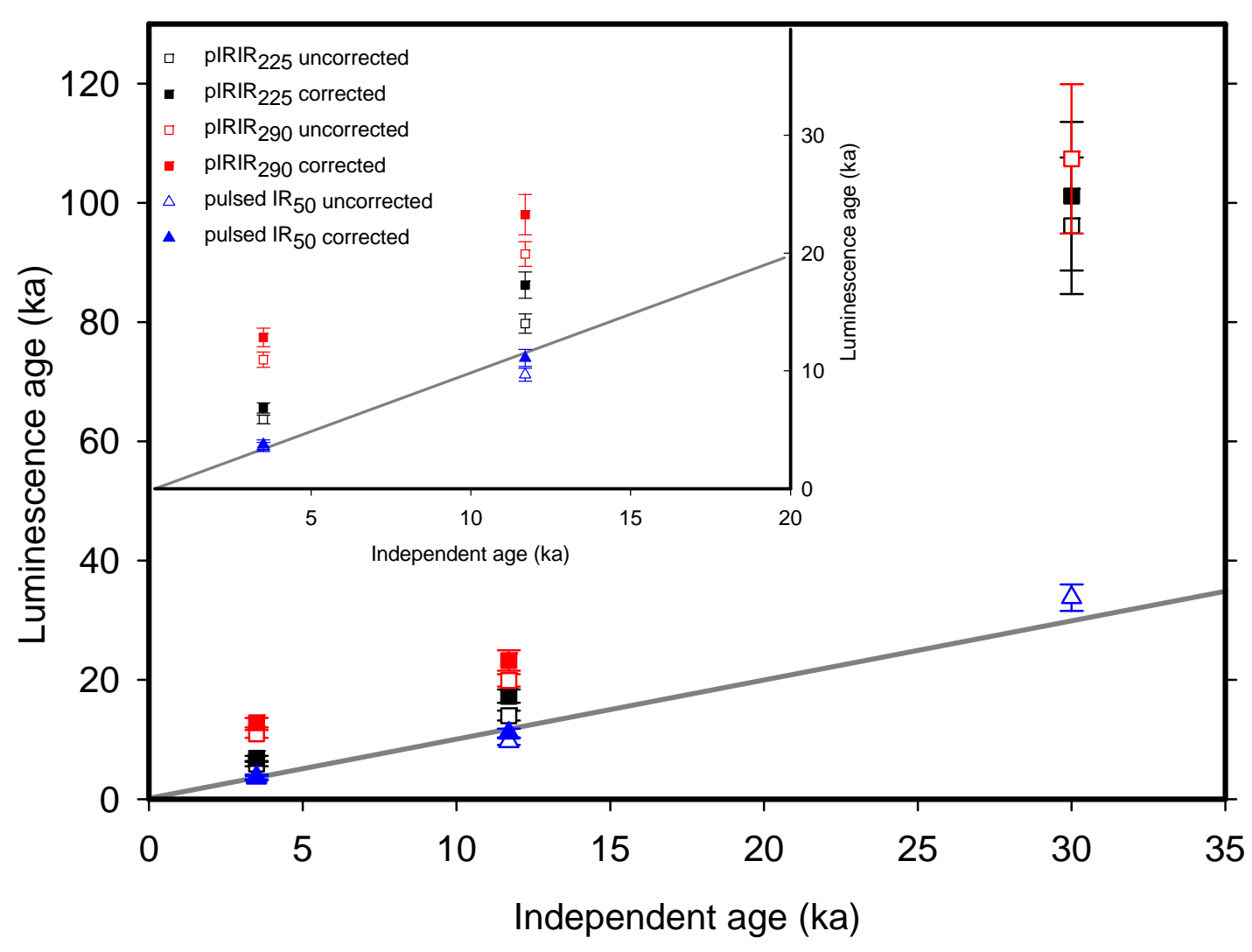

Fig. 9 